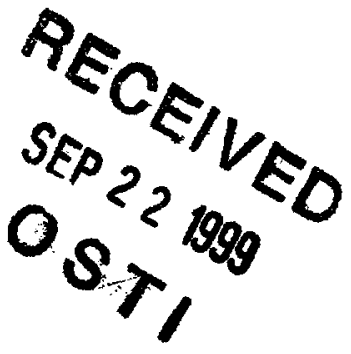

\title{
Trifluoromethylmetallate Anions as Components of Molecular Charge Transfer Salts and Superconductors
}

\author{
John A. Schlueter*a, Urs Geiser ${ }^{\mathrm{a}}$, Aravinda M. Kini ${ }^{\mathrm{a}}$, Hau H. \\ Wang $^{\mathrm{a}}$, Jack M. Williams ${ }^{\mathrm{a}}$, Dieter Naumann ${ }^{\mathrm{b}}$, Thomas Roy ${ }^{\mathrm{b}}$, \\ Berthold Hoge ${ }^{c}$, Reint Eujen ${ }^{c}$
}

\author{
${ }^{a}$ Chemistry and Materials Science Divisions, Argonne National \\ Laboratory, Argonne, Illinois 60439, USA
}
${ }^{ }$Institut für Anorganische Chemie, Universität Köln, Greinstrasse 6, $D$ - 50939 Köln, Germany

'Anorganische Chemie, Fachbereich 9, Universität-GH Wuppertal, 42097 Wuppertal, Germany 


\section{DISCLAIMER}

This report was prepared as an account of work sponsored by an agency of the United States Government. Neither the United States Government nor any agency thereof, nor any of their employees, make any warranty, express or implied, or assumes any legal liability or responsibility for the accuracy, completeness, or usefulness of any information, apparatus, product, or process disclosed, or represents that its use would not infringe privately owned rights. Reference herein to any specific commercial product, process, or service by trade name, trademark, manufacturer, or otherwise does not necessarily constitute or imply its endorsement, recommendation, or favoring by the United States Government or any agency thereof. The views and opinions of authors expressed herein do not necessarily state or reflect those of the United States Government or any agency thereof. 


\section{DISCLAIMER}

Portions of this document may be illegible in electronic image products. Images are produced from the best available original document. 


\section{Contents}

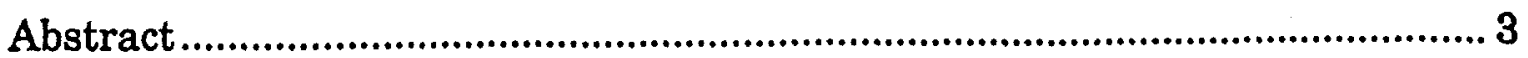

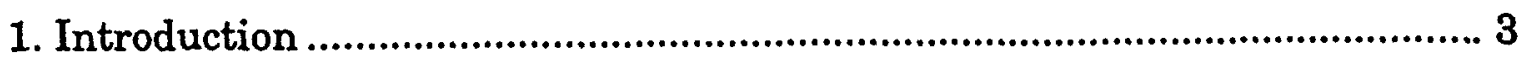

1.1. Historical perspective .............................................................................. 3

1.2. ET Salts of Group IB Metal Anions ......................................................... 6

1.4. ET Salts of Trifluoromethyl-based Anions …........................................... 8

1.5. A Prudent Choice of New Anions ........................................................... 8

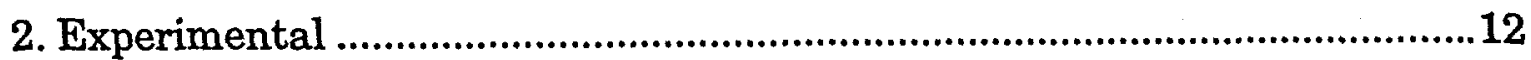

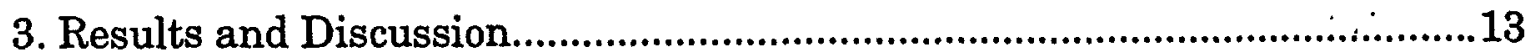

3.1. Extensive Tunability in Trifluoromethylmetallate Salts of ET ............13

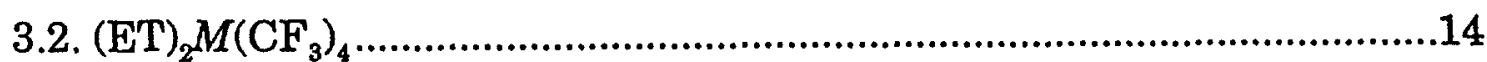

3.3. $\kappa_{\mathrm{L}}-(\mathrm{ET})_{2} M\left(\mathrm{CF}_{3}\right)_{4}(1,1,2$-trihaloethane $)$ Salts .......................................14

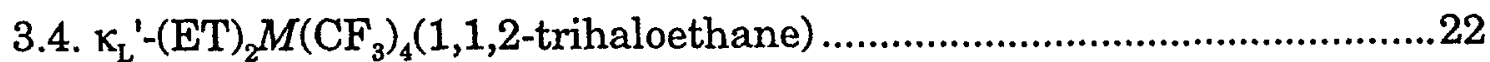

3.5. $\mathrm{K}_{\mathrm{H}}$-(ET) $\mathrm{E}_{2} M\left(\mathrm{CF}_{3}\right)_{4}(1,1,2$-trihaloethane) Salts ...................................22

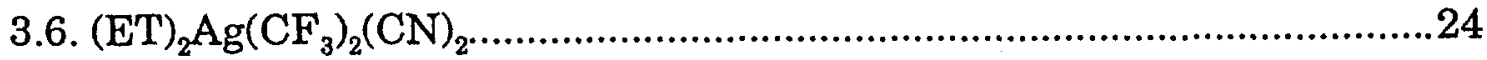

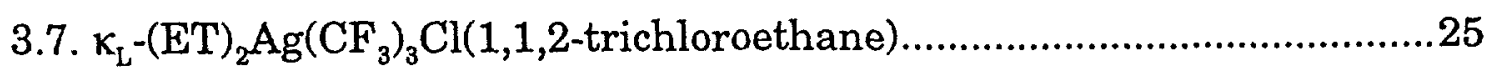

3.8. $\kappa_{\mathrm{L}}$-(BEDT-TSF $)_{2} \mathrm{Ag}\left(\mathrm{CF}_{3}\right)_{4}(1,1,2$-trichloroethane $)$..............................26

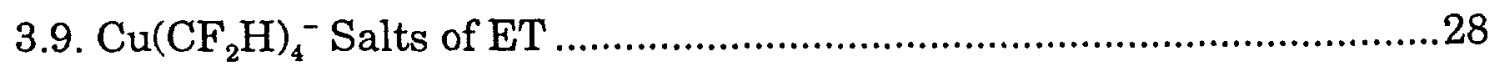

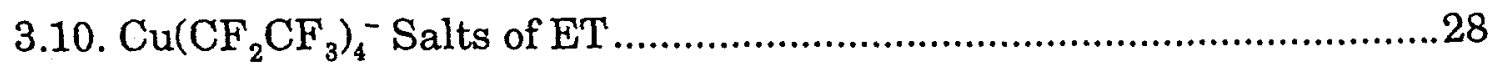

3.11. Trifluoromethyl metallate anion structural comparison .....................29

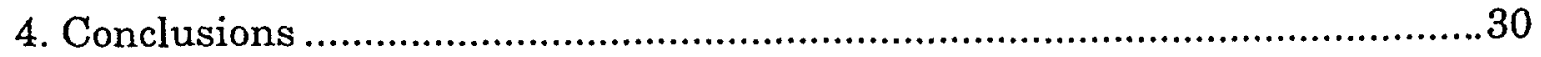

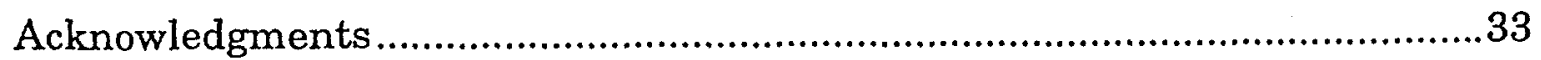

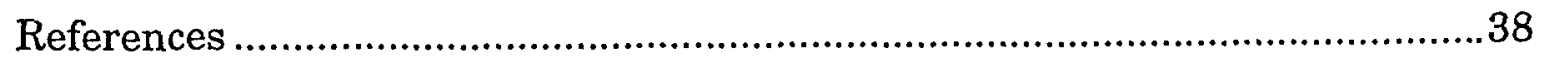




\section{Abstract}

Whereas polymeric and common inorganic anions frequently deprive the synthetic chemist of a chance to modify a charge transfer salt's structure through anion alterations, discrete organometallic anions provide a vast opportunity to probe the structure/property correlations of a material through rational synthetic methods. We have recently undertaken a research effort aimed at the crystallization of conducting charge transfer salts which possess modifiable, organometallic anions as the charge compensating entities. This research has been richly rewarded with the discovery of a new family of bis(ethylenedithio)tetrathiafulvalene (BEDT-TTF or ET) based molecular superconductors. Herein is presented a summary of over twenty $\kappa(\mathrm{ET})_{2} M\left(\mathrm{CF}_{3}\right)_{4}(1,1,2$-trihaloethane $)(M=\mathrm{Cu}, \mathrm{Ag}, \mathrm{Au})$ superconducting salts. Three new related salts are also reported: (ET) $)_{2}$ trans- $\left.\mathrm{Ag}\left(\mathrm{CF}_{3}\right)_{2}(\mathrm{CN})_{2}\right], \kappa_{\mathrm{L}}(\mathrm{BEDT}$ $\mathrm{TSF})_{2} \mathrm{Ag}\left(\mathrm{CF}_{3}\right)_{4}(\mathrm{TCE})$, and $\kappa_{\mathrm{L}}(\mathrm{ET})_{2} \mathrm{Ag}\left(\mathrm{CF}_{3}\right)_{3} \mathrm{Cl}(\mathrm{TCE})$.

Keywords: Organic superconductor, tetrakis(trifluoromethyl)metallate anions

\section{Introduction}

\subsection{Historical perspective}

Throughout history, organic compounds had been known as poor electrical conductors. About half a century ago, a revolutionary discovery indicated that the doping of large aromatic electron-donor molecules, such as perylene, resulted in large increases in conductivity. [1] This discovery prompted the preparation of a large number of highly conductive charge transfer salts, such as TTF•TCNQ, $[2,3]$ which were found to exhibit increasing conductivity with decreasing temperature: an intrinsic property of traditional metals. The electrocrystallization of the first organic superconductor, (TMTSF) ${ }_{2} \mathrm{PF}_{6}$, [4] began a new age in which many superconducting charge transfer salts were prepared through the use of discrete 
monovalent anions. As illustrated in Figure 1, these superconducting salts are comprised of thick conducting layers of electron-donor molecules separated by thinner insulating layers which contain the charge compensating anions.

Crystallization of simple, linear, discrete, inorganic anions, such as $\mathrm{I}_{3}^{-}, \mathrm{IBr}_{2}^{-}$, and $\mathrm{AuI}_{2}^{-}$, with the highly successful bis(ethylenedithio)tetrathiafulvalene (BEDTTTF or ET) electron-donor molecule resulted in the formation of a series of three isostructural superconducting salts. [5] One of the lessons learned through the development of structure/property relationships in the $\beta$-(ET) $)_{2} X\left(X=\mathrm{I}_{3}^{-}, \mathrm{IBr}_{2}^{-}\right.$, and $\mathrm{AuI}_{2}^{-} ; \beta$ represents one of the common packing motifs of the ET salts, as illustrated in Figure 2) family of organic superconductors was that larger anions lead to higher $T_{\mathrm{c}} \mathrm{s}$. By following this strategy of attempting to decrease the "lattice pressure" [6] by use of larger linear anions, a salt containing the $\mathrm{Cu}(\mathrm{NCS})_{2}^{-}$anion was prepared in 1988. [7] The $\mathrm{Cu}(\mathrm{NCS})_{2}{ }^{-}$anion in $\mathrm{K}-(\mathrm{ET})_{2} \mathrm{Cu}(\mathrm{NCS})_{2}$ was not linear as expected, but instead this was a superconducting ET salt containing a polymeric anion. The crystal structure was unique in that the ET molecules are not arranged in stacks, but rather in sheets containing perpendicularly arranged ET-molecule dimer units having short sulfur-sulfur contacts. Salts with this unique packing motif of ET molecules have been designated as K-phase materials (see Figure 2). The $10.4 \mathrm{~K} T_{\mathrm{c}}$ measured for the $\mathrm{K}-(\mathrm{ET})_{2} \mathrm{Cu}(\mathrm{SCN})_{2}$ salt pushed the superconducting transition temperature record for organic superconductors over $10 \mathrm{~K}$ for the first time.

In $1990, \kappa-(\mathrm{ET})_{2} \mathrm{Cu}\left[\mathrm{N}(\mathrm{CN})_{2}\right] \mathrm{Br}$ was electrocrystallized at Argonne National Laboratory. [8] This salt was found to have a superconducting transition temperature of $11.6 \mathrm{~K}$. By varying the halide constituents in this polymeric anion salt, an isostructural molecular metal was synthesized. The $\kappa-(\mathrm{ET})_{2} \mathrm{Cu}\left[\mathrm{N}(\mathrm{CN})_{2}\right] \mathrm{Cl}$ analog was shown to have an even higher $T_{\mathrm{c}}$ of $12.5 \mathrm{~K}$ under a mild hydrostatic 
pressure of $0.3 \mathrm{kbar}$. [9] The pressure required to suppress the magnetic transition that occurred at ambient pressure was so small that coating crystals of $\mathrm{K}$-(ET) ${ }_{2} \mathrm{Cu}$ $\left[\mathrm{N}(\mathrm{CN})_{2}\right] \mathrm{Cl}$ with varnish or Apiezon $\mathrm{N}$ stopcock grease created sufficient pressure to stabilize the superconducting state. [10]

Attempts to prepare superconductors which were isostructural to $\mathrm{k}$ $(\mathrm{ET})_{2} \mathrm{Cu}(\mathrm{SCN})_{2}$ or $\mathrm{K}-(\mathrm{ET})_{2} \mathrm{Cu}\left[\mathrm{N}(\mathrm{CN})_{2}\right] X(X=\mathrm{Cl}, \mathrm{Br})$ were quickly met with difficulties. The $\mathrm{Cu}(\mathrm{SCN})_{2}^{-}$and $\mathrm{Cu}\left[\mathrm{N}(\mathrm{CN})_{2}\right] X^{-}$anions are commonly formed during the electrocrystallization process by a not yet understood, and difficult to control "self-assembly" process. In the former case, the $\mathrm{Cu}(\mathrm{NCS})_{2}^{-}$anion was formed through the use of an electrolyte solution composed of KSCN, CuSCN, and 18crown-6. Modifications of this solution to contain $\mathrm{SeCN}^{-}$or $\mathrm{OCN}^{-}$ligands, or related metal centers failed to produce isostructural salts. Similarly, the $\mathrm{Cu}$ $\left[\mathrm{N}(\mathrm{CN})_{2}\right] X^{-}$anion is commonly formed in situ through the use of an electrolyte solution containing $\mathrm{PPh}_{4} \mathrm{~N}(\mathrm{CN})_{2}$ and $\mathrm{CuX}$, or a related electrolyte mixture. [11]

Through these research efforts, the $\mathrm{K}-(\mathrm{ET})_{2} \mathrm{Cu}_{2}(\mathrm{CN})_{3}$ salt was synthesized and found to have a superconducting state below $2.8 \mathrm{~K}$ under $1.5 \mathrm{kbar}$ pressure. [12] Shortly thereafter, a very similar salt, $\kappa^{\prime}-(\mathrm{ET})_{2} \mathrm{Cu}_{2}(\mathrm{CN})_{3}$, was reported to exhibit superconductivity at $3.8 \mathrm{~K}$ under ambient pressure. [13] Exchange of the halide in the $\kappa-(\mathrm{ET})_{2} \mathrm{Cu}\left[\mathrm{N}(\mathrm{CN})_{2}\right] X$ salts with $\mathrm{CN}$ has resulted in the preparation of $\kappa$ $(\mathrm{ET})_{2} \mathrm{Cu}(\mathrm{CN})\left[\mathrm{N}(\mathrm{CN})_{2}\right]$, which is an ambient pressure superconductor with $T_{\mathrm{c}}$ near $11 \mathrm{~K}$. [13] In this salt, the $\mathrm{Cu}(\mathrm{CN})\left[\mathrm{N}(\mathrm{CN})_{2}\right]^{-}$anion is not isostructural to $\mathrm{Cu}$ $\left[\mathrm{N}(\mathrm{CN})_{2}\right] \mathrm{X}^{-}$because the bridging ligands in the former are $\mathrm{CN}^{-}$groups whereas in the later, they are $\mathrm{N}(\mathrm{CN})_{2}^{-}$. Thus, although it is possible to synthesize new superconducting salts with polymeric anions, the rational design of the anion layer is still not possible. Without the ability to rationally synthesize isostructural salts, 
it is impossible to develop the structure/property relationships required to design materials with higher $T_{\mathrm{c}} \mathrm{s}$.

\subsection{ET Salts of Group IB Metal Anions}

Copper-based anions have been used fairly extensively for the synthesis of ET charge transfer salts, perhaps with hopes that they will yield superconducting salts with transition temperatures comparable to the high $T_{\mathrm{c}}$ copper oxides. The simplest of these is the linear $\mathrm{CuCl}_{2}^{-}$anion which crystallizes in several phases with ET. [1416] Several salts containing polymeric copper halide anions have been prepared such as $(\mathrm{ET}) \mathrm{Cu}_{2} \mathrm{Br}_{3},[17](\mathrm{ET}) \mathrm{Cu}_{3} \mathrm{I}_{4},[18]$ and $(\mathrm{ET})_{2} \mathrm{Cu}_{5} \mathrm{I}_{6}$. [19] The first example of the planar $\left[\mathrm{Cu}^{\mathrm{II}} X_{4}\right]^{2-}(X=\mathrm{Br}, \mathrm{Cl})$ anion was observed in the $(\mathrm{ET})_{3} \mathrm{CuBr}_{4}$ and $(\mathrm{ET})_{3} \mathrm{CuBr}_{2} \mathrm{Cl}_{2}$ structures. $[20,21] \mathrm{A}$ brief report of the $(\mathrm{ET})_{3} \mathrm{CuCl}_{4} \cdot \mathrm{H}_{2} \mathrm{O}$ structure has also been published. [22] The $(\mathrm{ET})_{4} \mathrm{Cu}\left(\mathrm{C}_{2} \mathrm{O}_{4}\right)_{2}$ salt has been found to be weakly metallic between 300 and $65 \mathrm{~K}$. [23] As stated above, the most important copper containing salts of $\mathrm{ET}$ are those possessing polymeric $\mathrm{Cu}(\mathrm{I})$ anions: $\mathrm{K}$ - $(\mathrm{ET})_{2} \mathrm{Cu}(\mathrm{SCN})_{2}$ or $\kappa-(\mathrm{ET})_{2} \mathrm{Cu}\left[\mathrm{N}(\mathrm{CN})_{2}\right] X(X=\mathrm{Cl}, \mathrm{Br})$. [7-9] Organometallic copper-based anions have not been studied as components in ET charge transfer salts, until this study.

There are relatively few examples of ET salts with silver-containing anions. The most common of these anions is $\mathrm{Ag}(\mathrm{CN})_{2}^{-}$, which crystallizes in several phases with ET. [5] The only one of these phase that exhibits a superconducting ground state is $\kappa-(\mathrm{ET})_{2} \mathrm{Ag}(\mathrm{CN})_{2} \cdot \mathrm{H}_{2} \mathrm{O}$, which has a superconducting transition at $5.0 \mathrm{~K}$. [24] Non-stoichiometric phases containing polymeric silver anions with $\mathrm{Br}^{-}, \mathrm{I}^{-}, \mathrm{CN}^{-}$, or $\mathrm{SCN}^{-}$ligands have also been reported. However, none of these non-stoichiometric silver-containing salts are superconducting. No ET salts have previously been reported to contain $\mathrm{Ag}(\mathrm{III})$ or organometallic anions. 
Linear $\mathrm{Au}(\mathrm{I})$ anions have been used extensively as components in ET-based charge transfer salts. ET salts containing the $\mathrm{AuI}_{2}^{-}, \mathrm{IAuBr}^{-}, \mathrm{AuBr}_{2}^{-}, \mathrm{AuCl}_{2}^{-}$, and $\mathrm{Au}(\mathrm{CN})_{2}^{-}$anions have been reported. [5] These salts crystallize with a large variety of structural motifs: $\beta, \beta^{\prime}, \beta^{\prime \prime}, \gamma^{\prime}, \delta, \alpha^{\prime}$, and $\eta$. The only one of these salts that is an ambient pressure superconductor is $\beta-(\mathrm{ET})_{2} \mathrm{AuI}_{2}$. [25]

Although square planar Au(III) anions have also been used to form ET-salts, the majority of these salts contain simple $\mathrm{Br}^{-}, \mathrm{Cl}^{-}$, or pseudo halide (i.e. $\mathrm{CN}^{-}$) ligands. X-ray crystal structures and physical properties of 2:1 (ET) ${ }_{2} \mathrm{AuCl}_{4}$ [26], (ET) ${ }_{2} \mathrm{AuBr}_{4},(\mathrm{ET})_{2} \mathrm{Au}(\mathrm{CN})_{2} \mathrm{Cl}_{2}[26]$, the 3:1 (ET) ${ }_{3} \mathrm{AuBr}_{4}$ [27] and the 1:1 (ET) $\mathrm{AuBr}_{2} \mathrm{Cl}_{2}$ [28] salts have been reported. The (ET)AuCl $\mathrm{AuCl}_{4}$ salt may contain the ET dication. [29]

A limited number of ET salts with gold anions possessing organic ligands have been prepared. While the structure of the $(\mathrm{ET})_{2}\left[\mathrm{Au}_{2}(\mathrm{imnt})_{2}\right]$ (imnt $=1,1-$ dithio-2,2-dicyanoethylene) salt has been reported, and shown to contain bridging $\mathrm{Au}^{\mathrm{I}}$ centers, [30] only a unit cell has been reported for the closely related (ET) [Au(imnt) ${ }_{2}$ ] salt which presumably contains a square planar $\mathrm{Au}^{\mathrm{III}}$ anion. [31] More recently, the (ET) $\left[\mathrm{Au}(\mathrm{dts})_{2}\right]$ (dts = dithiosquarate) salt has been found to contain integrated stacks of the ET electron-donor molecule and $\left[\mathrm{Au}(\mathrm{dts})_{2}\right]^{-}$, and possess semiconductive electrical properties. [32] We have recently reported the synthesis of the 1:1 complex $(\mathrm{ET}) \mathrm{Au}\left(\mathrm{C}_{6} \mathrm{Cl}_{5}\right)_{4}$ in which the phenyl rings of the novel organometallic $\mathrm{Au}\left(\mathrm{C}_{6} \mathrm{Cl}_{5}\right)_{4}{ }^{-}$anion completely surround the $\mathrm{ET}^{+1}$ cations. [33] 


\subsection{ET Salts of Trifluoromethyl-based Anions}

Relatively few ET salts have been reported which contain trifluoromethylbased anions. This may partially be due with the earlier philosophy that symmetric anions were required for the synthesis of superconducting charge transfer salts. The trifluoromethyl group also has a tendency to crystallize in a disordered configuration which would generally be expected to suppress the superconducting state. However, the $\mathrm{CF}_{3}$ group has the ability to form $\mathrm{F} \cdots \mathrm{H}$ interactions with the ET molecules. Such interactions are believed to influence the electrical properties of ET salts.

Prior to our work, no organometallic trifluoromethylmetallate anions had been crystallized with ET. The $(\mathrm{ET})_{2} \mathrm{CF}_{3} \mathrm{SO}_{3}$ salt has been reported to contain a disordered $\mathrm{CF}_{3} \mathrm{SO}_{3}^{-}$anion exhibit semiconductive properties. [34] We have recently reported the characterization of the small energy gap semiconductor $(\mathrm{ET})_{2}$ $\left[\mathrm{N}\left(\mathrm{SO}_{2} \mathrm{CF}_{3}\right)_{2}\right]$ which contains a severely disordered $\mathrm{N}\left(\mathrm{SO}_{2} \mathrm{CF}_{3}\right)_{2}^{-}$anion. [35]

\subsection{A Prudent Choice of New Anions}

We have recently pioneered a new approach for the synthesis of molecular superconductors. A major goal of this new direction is the preparation of isostructural series of charge transfer salts in which the physical properties can be fine tuned through anion modification. Ideally, a series would be able to be "tuned" to various superconducting transition temperatures. Such a family would yield valuable clues as to the structural ingredients necessary to produce superconducting salts with higher $T_{\mathrm{c}} \mathrm{s}$. 
By choosing to work with discrete anions, structural control is placed in the hands of the synthetic chemist rather than left to chance with self assembled polymeric structures. It is commonly possible to slightly alter the identity of such anions through chemical modifications prior to the electrocrystallization step. Such anions typically form salts with $\mathrm{TBA}^{+}, \mathrm{PPN}^{+}, \mathrm{PPh}_{4}{ }^{+}$, etc. which are easily soluble in organic solvents and can be readily purified through traditional methods.

With the previously learned knowledge that higher $T_{\mathrm{c}} \mathrm{s}$ can often be obtained through the use of larger anions, we decided to explore this vast, essentially untapped resource. Not only do these large molecular anions provide a logical route to higher superconducting transition temperatures, but they offer greater opportunity for chemical modification because they typically possess functional groups which can be chemically substituted. Organometallic anions are ideal candidates as components for superconducting charge transfer salts.

Although the conduction in molecular superconductors occurs through short intramolecular chalcogen $\cdots$ chalcogen contacts there is evidence that the hydrogen atoms on the ethylene end-groups of ET influence the superconducting state. It has been demonstrated that a significant increase in superconducting transition temperature occurs when the hydrogen atoms on the terminal ethylene groups of $\mathrm{ET}$ are replaced with deuterium in the $\mathrm{\kappa}-(\mathrm{ET})_{2} \mathrm{Cu}(\mathrm{SCN})_{2}$ superconductor. Thus, although these hydrogen atoms do not participate directly in the conduction mechanism, they have a significant influence on the superconducting state. [36-42] Crystallizing new superconducting charge-transfer salts with anions that have the ability to interact with these terminal hydrogen atoms will allow us to probe this important interaction. 
It has been shown that crystallographic disorder can be detrimental to superconductivity. An example of this is the (TMTSF) ${ }_{2} \mathrm{ClO}_{4}$ superconductor. [43] In order for these crystals to assume a superconducting state, they must be cooled slowly enough to allow the $\mathrm{ClO}_{4}^{-}$anions to undergo an ordering transition near 24 K. [44] A similar effect is seen in the isostructural $\beta$-(ET) $)_{2} X\left(X=\mathrm{I}_{3}^{-}, \mathrm{I}_{2} \mathrm{Br}^{-}, \mathrm{IBr}_{2}^{-}\right.$, and $\mathrm{AuI}_{2}^{-}$) family in which all members are superconductors except $\beta$-(ET) ${ }_{2} \mathrm{I}_{2} \mathrm{Br}$. It is believed that superconductivity does not occur in the $\beta$-(ET) ${ }_{2} \mathrm{I}_{2} \mathrm{Br}$ salt because the asymmetric $\mathrm{I}_{2} \mathrm{Br}^{-}$anion crystallizes in a random orientation. [45] Thus, when choosing new anions to crystallize with ET, those with higher symmetry are preferred.

Although superconducting salts have been formed with anions of many geometries (linear, tetrahedral, octahedral, planar, etc.), we feel that planar anions are preferable because they are conducive to packing in sheets: the desired arrangement of ET counterpart. Large anions with appendages perpendicular to the anion's molecular plane may be less likely pack tightly together in sheet-like networks. In fact, anions that have 'floppy' alkyl appendages will usually form poor quality crystals with a substantial degree of disorder, or not crystallize at all.

We feel that another important anion feature is the ability to delocalize the anion's charge over a large area of space. A localized negative charge may act as a trap, or a scatterer, and hinder Cooper pair formation. Although mononegative anions are preferred, larger anions with higher charges can also be successfully used. What seems to be important is the charge to volume ratio. Thus, a mononegative anion such as $\mathrm{CF}_{3} \mathrm{SO}_{3}{ }^{-}$should act similarly to a dinegative anion such as $\mathrm{O}_{3} \mathrm{SCF}_{2} \mathrm{CF}_{2} \mathrm{SO}_{3}{ }^{2-}$. 
Finally, the redox potentials of new anions must be considered. Strongly oxidizing anions must be avoided because they will chemically oxidize the ET molecules prior to the electrochemical step. Similarly, anions that are more easily oxidized than ET must be avoided because they will be electrochemically decomposed prior to the oxidation of the donor molecules.

The above criteria for anion selection should only be used to prioritize anions for use in the synthesis of new superconductors. It is felt that the more of these criteria that a new anion meets, the greater are its chances of forming a superconducting charge transfer salt. Of the myriad of known discrete anions, a vast number exist which fulfill the above criteria to various extents. These are the anions upon which our research efforts focus.

Through use of the previously described rationale, the $M\left(\mathrm{CF}_{3}\right)_{4}{ }^{-}(M=\mathrm{Cu}, \mathrm{Ag}$, Ag) anions were chosen as attractive candidates for the preparation of superconducting charge transfer salts. These large, discrete anions can be synthesized by chemical methods and isolated as pure salts of $\mathrm{PPN}^{+}$. [46] These PPN salts are stable in air under ambient conditions, and dissolve readily in organic solvents. The anions' large number of peripheral fluorine atoms allow for anion interactions with the terminal hydrogen atoms of the ET molecule. The mononegative charge is delocalized over the twelve fluorine atoms and this planar molecule has a relatively high degree of symmetry. The $M\left(\mathrm{CF}_{3}\right)_{4}^{-}$anion can be modified not only by changing the central metal atom but also by substitution of the $\mathrm{CF}_{3}$ ligand to produce anions of the type: $M\left(\mathrm{CF}_{2} \mathrm{CF}_{3}\right)_{4}^{-}, M\left(\mathrm{CHF}_{2}\right)_{4}^{-}, M\left(\mathrm{CF}_{3}\right)_{3}\left(\mathrm{CH}_{3}\right)^{-}$, $M\left(\mathrm{CF}_{3}\right)_{3} \mathrm{Cl}^{-}, \quad M\left(\mathrm{CF}_{3}\right)_{2}(\mathrm{CN})_{2}^{-}$, etc. We have initiated experiments aimed at determining how disorder intrinsic to these various anions affect the superconducting state. 


\section{Experimental}

ET was synthesized according to published methods, [47-50] and recrystallized from chloroform. $d_{8} \mathrm{ET}$, with deuterium atom substitution for all eight hydrogen atoms, was prepared in a parallel synthesis with ET through the use of $d_{4}$-1,2-dibromoethane (D,99\%). Bis(ethylenedithio)tetraselenafulvalene (BEDTTSF) was prepared by literature methods. [51] PPN $\left[M\left(\mathrm{CF}_{3}\right)_{4}\right]$ [PPN = bis(triphenylphosphoranylidene)ammonium, $M=\mathrm{Cu}, \mathrm{Ag}, \mathrm{Au}$ ] were prepared via the literature methods. $[46,52] \mathrm{PPN}\left[\mathrm{Ag}\left(\mathrm{CF}_{3}\right)_{3} \mathrm{Cl}\right]$ was prepared through the reaction of $\mathrm{Ag}\left(\mathrm{CF}_{3}\right)_{3}$ and PPN.Cl. [53] $\mathrm{PPN}\left[\mathrm{Cu}\left(\mathrm{CF}_{2} \mathrm{H}\right)_{4}\right]$ [54] and $\mathrm{PPh}_{4}\left[\right.$ trans-Ag( $\left.\left(\mathrm{CF}_{3}\right)_{2}(\mathrm{CN})_{2}\right]$ [55] were prepared according to the literature. Crystallization solvents were prepared and purified as previously described. [56]

Charge transfer salts were grown by electrocrystallization in standard $\mathrm{H}$ cells. ET (about $10 \mathrm{mg}$ ) was added to the anode chamber of an electrochemical cell containing a very fine porosity frit. About $25 \mathrm{mg}$ of the $\mathrm{PPN}^{+}$or $\mathrm{PPh}_{4}^{+}$salt of the desired anion was added to each chamber of the $\mathrm{H}$-cell in an argon-filled dry box. About $7.5 \mathrm{ml}$ of freshly distilled solvent was then added to each chamber of the cell. An initial current density of $0.2 \mu \mathrm{A} / \mathrm{cm}^{2}$ was applied. The current was increased daily, until crystal growth occurred. Crystals were grown at $25^{\circ} \mathrm{C}$ on platinum wire electrodes for a period of up to a month, harvested in air, and stored on dry ice. Crystals of (BEDT-TSF $)_{2} \mathrm{Ag}\left(\mathrm{CF}_{3}\right)_{4}(1,1,2$-trichloroethane) were grown in an analogous manner by replacing ET in the electrochemical cell with BEDT-TSF.

Magnetic studies were performed with a Lake Shore Cryotronics 7221 ac susceptometer operating with a $1 \mathrm{G}$ modulation field and a frequency of $125 \mathrm{~Hz}$. 
Through use of the sub-pot option, temperatures in the range 1.2-4.2 $\mathrm{K}$ were obtained. Samples were cooled in zero field over a time period of fifteen minutes. Magnetic susceptibility data were recorded while warming. The ESR measurements were performed with the use of an IBM ER-200 X-band spectrometer with a $\mathrm{TE}_{102}$ rectangular cavity. Low temperature experiments $(4-300 \mathrm{~K})$ were carried out with the use of an Oxford 900 flow-through cryostat and temperature controller. A strong-pitch standard ( $\mathrm{g}=2.0028$ ) was used for g-value calibration. Single crystal Xray diffraction was performed on a Siemens CCD-area detector based SMART system.

\section{Results and Discussion}

\subsection{Extensive Tunability in Trifluoromethylmetallate Salts of ET}

Unlike the TMTSF series of salts which tend to crystallize in one structural motif regardless of anion, the ET electron donor molecule has a propensity to crystallize in multiple phases even with the same anion. When the $M\left(\mathrm{CF}_{3}\right)_{4}{ }^{-}$anion is electrocrystallized with ET in 1,1,2-trichloroethane (TCE), four phases of crystals often grow simultaneously on the anode. These phases can be readily identified through their morphology and distinct ESR line widths: $\kappa_{\mathrm{L}}-(\mathrm{ET})_{2} M\left(\mathrm{CF}_{3}\right)_{4}(\mathrm{TCE})$ [hexagonal black plates, $\mathrm{LW}=50-70 \mathrm{G}$ ], $\kappa_{\mathrm{H}}-(\mathrm{ET})_{2} M\left(\mathrm{CF}_{3}\right)_{4}$ (TCE) [long, striated black needles, $\mathrm{LW}=5-7 \mathrm{G}$ ], $(\mathrm{ET})_{2} M\left(\mathrm{CF}_{3}\right)_{4}$ [smooth black rods, $\mathrm{LW}=30-40 \mathrm{G}$ ], and $\mathrm{\kappa}_{\mathrm{L}}{ }^{\prime-}$ $(\mathrm{ET})_{2} M\left(\mathrm{CF}_{3}\right)_{4}(\mathrm{TCE})$ [thick, black plates with slanted edges, $\left.\mathrm{LW}=45-55 \mathrm{G}\right]$. $[57,58]$ A summary of the unit cell parameters for salts of trifluoromethylmetallate anions is given in Table 1. 


\section{2. $\left(\mathrm{ET}_{2} \mathrm{M}\left(\mathrm{CF}_{2}\right)_{4}\right.$}

Crystals of the $(\mathrm{ET})_{2} M\left(\mathrm{CF}_{3}\right)_{4}$ phase typically grow with a rod-like morphology. [59] As with most ET salts, this structure contains alternating layers of anions and ET molecules. A projection of the $(\mathrm{ET})_{2} \mathrm{Ag}\left(\mathrm{CF}_{3}\right)_{4}$ structure on the $b c$-plane is illustrated in Figure 3. Within the layers, there are two stacks of ET molecules which are related to each other by a screw axis: a motif typical of $\theta$-phase salts. [60] Within this structure, the $M\left(\mathrm{CF}_{3}\right)_{4}^{-}$anions lie on an inversion center and have ordered trifluoromethyl groups and a planar $M \mathrm{C}_{4}$ core. (See Figure 4.) As is frequently the case in ET salts, one of the ethylene groups of the ET molecule is conformationally disordered at room temperature. A few short intermolecular $\mathrm{CH}_{2}-$ F contacts (less than the sum of the van der Waals radii, $2.67 \AA$ ) are present in the $(\mathrm{ET})_{2} M\left(\mathrm{CF}_{3}\right)_{4}$ salts, with the shortest being $2.47 \AA$.

The ESR spectrum of $(\mathrm{ET})_{2} \mathrm{Cu}\left(\mathrm{CF}_{3}\right)_{4}$ measured between 300 and $4 \mathrm{~K}$ indicates that the spin susceptibility of this material follows Curie-Weiss behavior, typical of a paramagnetic semiconductor. [57] The room temperature line width of $35 \mathrm{G}$ decreased with temperature to $70 \mathrm{~K}$, at which point an uncharacterized phase transition was observed. As shown in Figure 5, four-probe conductivity measurements indicate that the $(\mathrm{ET})_{2} \mathrm{Ag}\left(\mathrm{CF}_{3}\right)_{4}$ is a semiconductor, with an activation energy of about $0.19 \mathrm{eV}$.

\section{3. $\kappa_{\mathrm{L}}$-(ET) $)_{2} M\left(\mathrm{CF}_{3}\right)_{4}(1,1,2$-trihaloethane $)$ Salts}

Crystals of the plate-like phase, grown from TCE, were found to have superconducting transition temperatures of $4.0 \mathrm{~K}\left[\mathrm{Cu}\left(\mathrm{CF}_{3}\right)_{4}^{-}\right],[61] 2.6 \mathrm{~K}\left[\mathrm{Ag}\left(\mathrm{CF}_{3}\right)_{4}^{-}\right]$, [62] and $2.1 \mathrm{~K} \quad\left[\mathrm{Au}\left(\mathrm{CF}_{3}\right)_{4}^{-}\right]$. [63] An x-ray diffraction study of these hexagonal crystals revealed a $\kappa$-type arrangement of ET molecules (See Figure 2), with the 
donor layers isostructural to the $\mathrm{K}-(\mathrm{ET})_{2} \mathrm{Cu}\left[\mathrm{N}(\mathrm{CN})_{2}\right] X(X=\mathrm{Cl}, \mathrm{Br})$ superconducting salts. [64] In addition to $M\left(\mathrm{CF}_{3}\right)_{4}^{-}$anions, the anion layer was found to contain an equal number of neutral TCE solvent molecules. These plate-like crystals have thus been given the designation $\mathrm{K}_{\mathrm{L}}-(\mathrm{ET})_{2} M\left(\mathrm{CF}_{3}\right)_{4}(\mathrm{TCE})$ (the subscript, $\mathrm{L}$, designates the lower $T_{\mathrm{c}}$ phase).

In the $\kappa_{\mathrm{L}}$-phase, both the anion and solvent molecules were found to lie on a mirror plane and were crystallographically disordered. Whereas the trifluoromethyl groups of the anion in PPN $\left[\mathrm{Cu}\left(\mathrm{CF}_{3}\right)_{4}\right]$ lie on a mirror plane, the crystallographic mirror plane in $\kappa_{\mathrm{L}}-(\mathrm{ET})_{2} \mathrm{Cu}\left(\mathrm{CF}_{3}\right)_{4}(\mathrm{TCE})$ bisects the anion's $\mathrm{C}-\mathrm{Cu}-\mathrm{C}$ angles. For steric reasons, adjacent trifluoromethyl groups cannot be related by a mirror plane, and are therefore crystallographically disordered. In the $\kappa_{\mathrm{L}}$ $(\mathrm{ET})_{2} \mathrm{Ag}\left(\mathrm{CF}_{3}\right)_{4}(\mathrm{TCE})$ salt, the longer $M-\mathrm{C}$ distance reduces the steric interactions between adjacent $\mathrm{CF}_{3}$ groups. Numerous contacts, shorter than the sum of the corresponding van der Waals radii, exist between the fluorine atoms of the $M\left(\mathrm{CF}_{3}\right)_{4}^{-}$ anions and the adjacent hydrogen atoms of both the ET and TCE molecules. These contacts are believed to be important both for stabilizing the structure and for the occurrence of superconductivity.

The anion layer in the $\mathrm{K}_{\mathrm{L}}$-structure is the thickest known for any molecular superconductor: more than twice as thick as in $\kappa-(\mathrm{ET})_{2} \mathrm{Cu}\left[\mathrm{N}(\mathrm{CN})_{2}\right] \mathrm{Br}(8.3 \AA$ vs. 3.9 $\AA$ ) (See Figure 6). Thus, $\kappa_{\mathrm{L}}-(\mathrm{ET})_{2} M\left(\mathrm{CF}_{3}\right)_{4}(\mathrm{TCE})$ is a very two-dimensional system with direct communication between adjacent ET layers improbable. Superconductivity is a bulk property, and electron transport through the anion layer must occur, even in the normal state. Thus, it is probable that the anion or solvent molecules contribute in some capacity to the electron transport in these materials. It is somewhat surprising that even with the extensive anion-layer 
disorder, the $\mathrm{K}_{\mathrm{L}}-(\mathrm{ET})_{2} M\left(\mathrm{CF}_{3}\right)_{4}(\mathrm{TCE})$ salts exhibit a superconducting ground state. It is possible that the trifluoromethyl groups order as the crystal is cooled below $100 \mathrm{~K}$, because this disorder is simply a result of rotation about the $M-\mathrm{C}$ bonds. However, it is much more unlikely that disorder in the solvent position could be eliminated by cooling because this would require a molecular reorganization, rather than a simple bond rotation. As in $\mathrm{K}-(\mathrm{ET})_{2} \mathrm{Cu}\left[\mathrm{N}(\mathrm{CN})_{2}\right] \mathrm{Br},[65]$ the ethylene groups of the ET molecule were found to be ordered in an eclipsed conformation at $120 \mathrm{~K}$, and presumably, remain ordered in the superconducting state.

The three component (electron donor molecule, anion, and cocrystallized solvent) aspect of this system provides an even greater versatility than expected. Additional superconductors were synthesized through solvent exchange. [56] By replacing the chlorine atoms on the TCE solvent molecule with bromine, four closely related solvent molecules were synthesized and cocrystallized in the $\kappa_{\mathrm{L}}$ (ET) ${ }_{2} M\left(\mathrm{CF}_{3}\right)_{4}(1,1,2$-trihaloethane) structure. A tabulation of the superconducting transition onset temperatures for the fifteen known $\kappa_{\mathrm{L}}-(\mathrm{ET})_{2} M\left(\mathrm{CF}_{3}\right)_{4}(1,1,2-$ trihaloethane) superconductors is given in Table 2.

The solvent molecule in the $\kappa_{\mathrm{L}}-(\mathrm{ET})_{2} M\left(\mathrm{CF}_{3}\right)_{4}(1,1,2$-trihaloethane) structure is located on a mirror plane, and thus crystallographically disordered. The halogen positions of the two orientations of the cocrystallized solvent molecule are superimposed, forming an isosceles triangle. (See Figure 7.) The one halogen position, $\mathrm{A}$, lies on the mirror plane, while the other two positions, $\mathrm{B}$ and $\mathrm{B}^{\prime}$, are related by symmetry. The 1,1,2-trihaloethanes can be classified as three types. Solvent molecules in which the three halogens are of the same type, as in 1,1,2trichloroethane and 1,1,2-tribromoethane, are classified as Type I. The $\mathrm{K}_{\mathrm{L}^{-}}$ $(\mathrm{ET})_{2} M\left(\mathrm{CF}_{3}\right)_{4}(1,1,2$-trihaloethane) structures which contain Type I solvent molecules 
have no mixed occupancy on the halogen sites. Both sites $A$ and $B$ must contain $100 \%$ chlorine or bromine. Type II solvents include 1-bromo-1,2-dichloroethane and 1,2-dibromo-1-chloroethane, which contain the unique halogen atom on the ethane's disubstituted position. Both of these solvent molecules are chiral. For Type II solvents, site A would result in a 50/50 mixture of both chlorine and bromine, while site $B$ would be composed of $25 \%$ of the unique halogen and $75 \%$ on the non-unique halogen type. However, if preferential ordering occurred, the unique halogen atom could lie on site A $100 \%$ of the time, with the non-unique one forced to reside on the B sites. Type III solvents include 2-bromo-1,1-dichloroethane and 1,1-dibromo-2chloroethane, which contain the unique halogen atom on the ethane's monosubstituted carbon. If no preferential ordering occurs, the B sites would contain a 50/50 mixture of the two halogen elements. For Type III solvents, the unique halogen atom will never lie on site A. Thus, for Type II solvents, the unique halogen atom could lie on site A $100 \%$ of the time, whereas for Type III solvents, it can never lie on this site.

The 1,1-dibromo-2-chloroethane solvent has not yet been prepared, but it is highly likely that this solvent will yield three additional superconducting salts with the $\kappa_{\mathrm{L}}$-structure. 1,1,2-trihaloethane solvents which contain iodine are unstable, decomposing into the corresponding haloethane and elemental halogen, thus preventing solvated salts from being prepared with these iodinated solvents. When one or more of the chlorine atoms of the 1,1,2-trihaloethane solvent molecule are replaced with fluorine, the non-solvated, rod-like phase forms exclusively. This may be a result of the fluorinated solvent competing with the $M\left(\mathrm{CF}_{3}\right)_{4}^{-}$anion for $\mathrm{H} \cdots \mathrm{F}$ contacts during the crystallization process. Thus, all chlorinated and/or brominated 1,1,2-trihaloethane solvents form solvated, superconducting $\kappa_{\mathrm{L}}-(\mathrm{ET})_{2} M\left(\mathrm{CF}_{3}\right)_{4}(1,1,2-$ 
trihaloethane) salts, whereas all other solvents have not formed the desired kappatype phase, and do not superconduct.

Through an examination of the superconducting transition temperatures listed for the $\kappa_{\mathrm{L}}-(\mathrm{ET})_{2} M\left(\mathrm{CF}_{3}\right)_{4}(1,1,2$-trihaloethane) salts in Table 2, it can be seen that all salts which contain the 1-bromo-1,2-dichloroethane solvent molecule have $T_{c}$ 's more then $1 \mathrm{~K}$ lower than the corresponding 2-bromo-1,1-dichloroethane salts, although these solvent molecules have the same physical size. The difference between these molecules is that 1-bromo-1,2-dichloroethane is a Type II solvent while 2-bromo-1,1-dichloroethane is a Type III solvent. Thus, the bromine atom of 1-bromo-1,2-dichloroethane can lie on site A $100 \%$ of the time, while when 2-bromo1,1-dichloroethane is the solvent, the bromine atom is forced to lie on the B sites. Site A lies on the crystallographic mirror plane, and substitution of a larger halogen on this site results in an expansion within the anion layer. However, the B sites point perpendicular to the anions layer, and placement of a larger halogen on these sites results in an expansion perpendicular to the anions layer, pushing the ET layers further apart. This lattice expansion perpendicular to the conducting planes is in contrast to that observed in the $\beta-(\mathrm{ET})_{2} X$ salts, where the linear trihalide anions lie nearly parallel to the stacking axis, and replacement of the $\mathrm{I}_{3}^{-}$anion for $\mathrm{IBr}_{2}^{-}$results in an expansion nearly parallel to the ET stacking axis. $[66,67]$ These results from the $\kappa_{\mathrm{L}}-(\mathrm{ET})_{2} M\left(\mathrm{CF}_{3}\right)_{4}(1,1,2$-trihaloethane) family of salts supports the previously mentioned notion that higher $T_{\mathrm{c}} \mathrm{s}$ can, to some extent, be obtained through the use of larger anions which expand the crystalline lattice.

A preliminary systematic X-ray characterization of the $\kappa_{\mathrm{L}}-(\mathrm{ET})_{2} M\left(\mathrm{CF}_{3}\right)_{4}(1,1,2-$ trihaloethane) family of salts has indicated that there is a correlation between the unit cell parameters and the superconducting transition temperature. [68] The unit 
cell parameters for several $\kappa_{\mathrm{L}}$-(ET) $)_{2} M\left(\mathrm{CF}_{3}\right)_{4}(1,1,2$-trihaloethane) salts, both at room temperature and $118 \mathrm{~K}$, are listed in Table 1. The relationship between $T_{c}$ and the unit cell parameters is not a simple on, and depends on the ratio of the $b$-and $c$-axis lengths. Undoubtedly, the $T_{\mathrm{c}}$ depends on something much more profound than simply unit cell lengths. Slight variations in intermolecular contacts may have significant influence on the superconducting state. It is likely that once the complete characterization of the $M\left(\mathrm{CF}_{3}\right)_{4}^{-}$salts is achieved, it will be possible to develop structure-property correlations for these systems that will lead to an even larger number of novel organic superconductors. The details of these structure/property relationships are currently being developed.

An additional degree of tunability in the $\kappa_{\mathrm{L}}-(\mathrm{ET})_{2} M\left(\mathrm{CF}_{3}\right)_{4}(1,1,2$-trihaloethane) system can be found through the use of mixed solvents. As illustrated in Figure 8, the superconducting transition temperature can be adjusted through the composition of the solvent. The $\kappa_{\mathrm{L}}-(\mathrm{ET})_{2} \mathrm{Ag}\left(\mathrm{CF}_{3}\right)_{4}(1,1,2$-trichloroethane) has a superconducting transition at $2.4 \mathrm{~K}$, while the $\kappa_{\mathrm{L}}-(\mathrm{ET})_{2} \mathrm{Ag}\left(\mathrm{CF}_{3}\right)_{4}(1,1,2-$ tribromoethane) analog has a higher $T_{\mathrm{c}}$ of $4.8 \mathrm{~K}$. By using mixed solvent systems containing various ratios of 1,1,2-trichloroethane and 1,1,2-tribromoethane, crystals of the general formula $\kappa_{\mathrm{L}}$-(ET) ${ }_{2} \mathrm{Ag}\left(\mathrm{CF}_{3}\right)_{4}(1,1,2 \text {-trichloroethane) })_{\mathbf{x}}(1,1,2-$ tribromoethane) $)_{1-x}$ can be prepared yielding any desired $T_{c}$ in the 2.4 to $4.8 \mathrm{~K}$ range.

An even greater degree of disorder will be present in these mixed solvent salts, because in addition to the disordered solvent molecules and trifluoromethyl groups, a random mixture of TBE and TCE is expected on the solvent sites. While it could be expected that mixed solvents could result in a broad superconducting transition, spanning the $2.4-4.8 \mathrm{~K}$ range, it is noted that these crystals have sharp superconducting transitions, similar to those observed for crystals containing only 
one solvent. Mixing halogens on the cocrystallized solvent molecules seems to affect the superconducting transition temperature by causing small shifts in the packing motif of the donor layer. There are no short contacts between the hydrogen atoms of ET and the halogen atoms of the cocrystallized solvent. If such contacts existed, the random potentials caused by the mixed halogens could be detrimental to superconductivity. This may explain why halogen disorder in the $\kappa_{\mathrm{L}}$ $(\mathrm{ET})_{2} M\left(\mathrm{CF}_{3}\right)_{4}(1,1,2$-trihaloethane) salts does not destroy superconductivity as it does in the $\beta-(\mathrm{ET})_{2} X$ family. [45] It is expected that similar control of the superconducting transition could be obtained through mixed anion systems such as $\kappa_{\mathrm{L}}-(\mathrm{ET})_{2} \mathrm{Cu}_{x} \mathrm{Au}_{1 \cdot-x}\left(\mathrm{CF}_{3}\right)_{4}(1,1,2$-trichloroethane). In such salts, the random placements of the mixed metals would influence the conducting layer only indirectly, and superconductivity would be expected to occur. A potentially different situation could occur if some of the fluorine atoms of the anion's $\mathrm{CF}_{3}$ groups were randomly replaced with hydrogen. Such a substitution could have a more severe impact on superconductivity because these fluorine atoms are in intimate contact with the important hydrogen atoms of ET.

We have investigated the effect of isotopic substitution upon $T_{c}$ in the $\kappa_{L^{-}}$ $(\mathrm{ET})_{2} \mathrm{Ag}\left(\mathrm{CF}_{3}\right)_{4}$ (1-bromo-1,2-dichloroethane) superconductor. [69] Our results indicate that deuterium substitution on the ethylene end groups of ET cause an increase in $T_{c}$ from $2.90 \mathrm{~K}$ to $3.11 \mathrm{~K}$ (based on the linearly extrapolated mean-field $T_{\mathrm{c}}$ ). Similar to $\mathrm{K}-(\mathrm{ET})_{2} \mathrm{Cu}(\mathrm{SCN})_{2}$, this isotopic shift is opposite in sign to that predicted based on a BCS-like phonon model. In fact, the $\Delta T_{c} / T_{\mathrm{c}}$ value of 0.072 for $\mathrm{K}_{\mathrm{L}}$ $(\mathrm{ET})_{2} \mathrm{Ag}\left(\mathrm{CF}_{3}\right)_{4}(1$-bromo-1,2-dichloroethane) is more than twice the magnitude of 0.033 observed for $\kappa-(\mathrm{ET})_{2} \mathrm{Cu}(\mathrm{SCN})_{2}$. In a similar experiment, we have found that a slightly larger shift in $T_{\mathrm{c}}$ occurs in the isostructural $\kappa_{\mathrm{L}}$-(ET) $)_{2} \mathrm{Ag}\left(\mathrm{CF}_{3}\right)_{4}(\mathrm{TBE})$ salt. [70] For this salt, $\Delta T_{\mathrm{cl}}=0.36 \pm 0.13 \mathrm{~K}$ and $\Delta T_{\mathrm{c}} / T_{\mathrm{c}}=0.079$. This evidence confirms the fact 
that the ethylene groups of ET have a very significant influence on the superconducting state even though they do not directly contribute to the conduction band. It will be possible to probe this important interaction with the use of modifiable, discrete anions that have the ability to interact with these hydrogen atoms.

The room temperature ESR line widths of the $\kappa_{\mathrm{L}}-(\mathrm{ET})_{2} M\left(\mathrm{CF}_{3}\right)_{4}(1,1,2-$ trihaloethane) salts range from 54-68 G. [57] These values are typical of other $\mathrm{k}$ phase organic superconductors such $\kappa-(\mathrm{ET})_{2} \mathrm{Cu}(\mathrm{SCN})_{2} \quad[71]$ and $\kappa-(\mathrm{ET})_{2} \mathrm{Cu}$ $\left[\mathrm{N}(\mathrm{CN})_{2}\right] \mathrm{Br}$. [72] A maximum in the ESR line width is observed near $100 \mathrm{~K}$, comparable to the maximum observed in the variable temperature resistivity data.

The electronic band structure of $\kappa_{\mathrm{L}}-(\mathrm{ET})_{2} \mathrm{Cu}\left(\mathrm{CF}_{3}\right)_{4}(1,1,2$-trihaloethane) was calculated based on the room temperature structure of this salt. [73] Based on this calculation, two-dimensional electronic properties similar to $\mathrm{k}-(\mathrm{ET})_{2} \mathrm{Cu}\left[\mathrm{N}(\mathrm{CN})_{2}\right] \mathrm{Br}$ are expected. [8]

A strongly negative pressure derivative has been determined for the $\kappa_{\mathrm{L}}$ $(\mathrm{ET})_{2} M\left(\mathrm{CF}_{3}\right)_{4}(\mathrm{TCE})(M=\mathrm{Cu}, \mathrm{Ag})$ salts. The $\mathrm{d} T_{c} / \mathrm{dP}$ values range from -2 to -3 $\mathrm{K} / \mathrm{kbar}$, and are typical of cation-radical organic superconductors. [61, 62, 74] Although the pressure study indicates that higher $T_{c} \mathrm{~s}$ can be obtained through the use of larger anions, the trend in $T_{c}$ for the $\kappa_{\mathrm{L}}-(\mathrm{ET})_{2} M\left(\mathrm{CF}_{3}\right)_{4}(\mathrm{TCE})$ salts is that $M=$

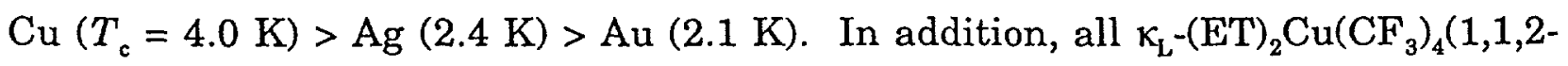
trihaloethane) salts have higher $T_{\mathrm{c}} \mathrm{s}$ than the corresponding $\kappa_{\mathrm{L}}-(\mathrm{ET})_{2} \mathrm{Ag}\left(\mathrm{CF}_{3}\right)_{4}(1,1,2-$ trihaloethane) salts (see Table 1 ). It is evident that the $T_{\mathrm{c}}$ depends on more than one controlling factor. Studies are currently in progress to better understand these factors. 
The solvated $M\left(\mathrm{CF}_{3}\right)_{4}^{-}$salts tend to slowly lose their cocrystallized solvent under ambient conditions, building up a crust of the $(\mathrm{ET})_{2} M\left(\mathrm{CF}_{3}\right)_{4}$ phase on the surface of the crystal. [56] ESR studies have confirmed this finding, and indicated that increased temperatures accelerate this process. [57] However, the superconducting state of these salts can be preserved for months if they are stored at dry ice temperatures.

\section{4. $K_{\mathrm{L}}{ }^{\prime}-(\mathrm{ET})_{2} M\left(\mathrm{CF}_{3}\right)_{4}(1,1,2$-trihaloethane $)$}

A crystallographic phase closely related to $\kappa_{\mathrm{L}}-(\mathrm{ET})_{2} M\left(\mathrm{CF}_{3}\right)_{4}(1,1,2-$ trihaloethane) has been identified. These crystals grow as thick plates with slanted edges. [75] Whereas adjacent layers in $\kappa_{\mathrm{L}}-(\mathrm{ET})_{2} M\left(\mathrm{CF}_{3}\right)_{4}(1,1,2$-trihaloethane) are related by a mirror plane and are tilted in alternating orientations, every electron-donor molecule layer in $\kappa_{L}{ }^{\prime}-(\mathrm{ET})_{2} M\left(\mathrm{CF}_{3}\right)_{4}(1,1,2$-trihaloethane) is tilted in the same direction. Low temperature ESR measurements of the spin susceptibility and line width indicate that $\mathrm{K}_{\mathrm{L}}{ }^{\prime}$-(ET) ${ }_{2} M\left(\mathrm{CF}_{3}\right)_{4}(1,2$-dibromo-1-chloroethane) is metallic between 140 and $10 \mathrm{~K}$. [58] These crystals grow as a minor phase, and currently, little is known about its other physical properties. It is hoped that through modified crystallization conditions, additional crystals of this phase will become available, and the effect of this slight structural modification on the physical properties will be determined.

\section{5. $\kappa_{\mathrm{H}}$-(ET) $)_{2} M\left(\mathrm{CF}_{3} L_{1}(1,1,2\right.$-trihaloethane) Salts}

The needle-like morphology has significantly higher transition temperatures of $9.2 \mathrm{~K}\left[\mathrm{Cu}\left(\mathrm{CF}_{3}\right)_{4}^{-}\right],[74] 11.1 \mathrm{~K}\left[\mathrm{Ag}\left(\mathrm{CF}_{3}\right)_{4}^{-}\right]$, [62] and $10.5 \mathrm{~K}\left[\mathrm{Au}\left(\mathrm{CF}_{3}\right)_{4}^{-}\right]$, than the corresponding $\kappa_{\mathrm{L}}$ salts. [63] An EDAX characterization suggested that the 
elemental composition of the striated needles is also very similar to the plates in that the ET/anion/solvent ratio is 2:1:1. The needle-like morphology's tendency to grow as bundles of fine needles has hampered our efforts to determine this phase's crystal structure. Preliminary $x$-ray diffraction from a twinned crystal indicated that the unit cell may be similar to the plate-like phase except doubled along the $c$ axis. [56] The needle-like morphology has been designated $\kappa_{\mathrm{H}}-(\mathrm{ET})_{2} M\left(\mathrm{CF}_{3}\right)_{4}(\mathrm{TCE})$ ( $\mathrm{H}$ designates the higher $T_{\mathrm{c}}$ phase) under the preliminary assumption that this phase also has a $\mathrm{k}$-type packing motif.

So far six $\kappa_{\mathrm{H}}$-(ET) $)_{2} M\left(\mathrm{CF}_{3}\right)_{4}(1,1,2$-trihaloethane) salts have been prepared. To date, these higher $T_{c}$ materials contain either the $\mathrm{Ag}\left(\mathrm{CF}_{3}\right)_{4}^{-}$anion or the TCE solvent molecule but there is every reason to believe that additional $\kappa_{\mathrm{H}}$-salts will be prepared through the use of the less stable brominated solvents when combined with the $\mathrm{Cu}\left(\mathrm{CF}_{3}\right)_{4}^{-}$and $\mathrm{Au}\left(\mathrm{CF}_{3}\right)_{4}^{-}$anions.

The four-probe, variable temperature resistivity measurements of $\kappa_{\mathrm{H}^{-}}$ $(\mathrm{ET})_{2} M\left(\mathrm{CF}_{3}\right)_{4}(\mathrm{TCE})$ salts have a profile similar to other $\kappa$-phase salts. The resistivity increases by a factor of about 250 with decreasing temperature from room temperature down to about $90 \mathrm{~K}$. $[62,74]$ This relative increase in resistivity is considerably greater than that observed in $\kappa-(\mathrm{ET})_{2} \mathrm{Cu}(\mathrm{SCN})_{2},[76,77]$ and may be a result of the fibrous nature of the $\kappa_{\mathrm{H}}$ crystals. Below $90 \mathrm{~K}$, the resistivity decreases in a metallic fashion until the superconducting transition is reached.

The dependence of $T_{\mathrm{c}}$ on pressure for the $\kappa_{\mathrm{H}}$-phase is very similar to that observed for the $\kappa_{\mathrm{L}}$-phase, and typical of ET-based superconductors in general. The pressure derivative was found to be $\mathrm{d} T / \mathrm{d} P=-1.9 \mathrm{~K} / \mathrm{kbar}$. [62] The negative value again indicates that expansion of the unit cell may result in higher superconducting 
transition temperatures. In contrast to the $\kappa_{\mathrm{L}}$-phase, the $\kappa_{\mathrm{H}}$ - $(\mathrm{ET})_{2} \mathrm{Ag}\left(\mathrm{CF}_{3}\right)_{4}(\mathrm{TCE})$ has a higher $T_{\mathrm{c}}(11.1 \mathrm{~K})[62]$ than $\mathrm{K}_{\mathrm{H}}-(\mathrm{ET})_{2} \mathrm{Cu}\left(\mathrm{CF}_{3}\right)_{4}(\mathrm{TCE})\left(T_{\mathrm{c}}=9.2 \mathrm{~K}\right)$. [74] The lack of $\kappa_{\mathrm{H}}$-(ET) $)_{2} M\left(\mathrm{CF}_{3}\right)_{4}(1,1,2$-trihaloethane $)(M=\mathrm{Cu}$ or $\mathrm{Au})$ salts containing brominated solvents currently prevents a more complete analysis of the effect of the cocrystallized solvent in the $\kappa_{\mathrm{H}}$-phase salts. [68] A study aimed at addressing this question is currently in progress.

The narrow ESR line width of the $\kappa_{\mathrm{H}}$-salts is rather unique among ET-based organic superconductors. An explanation for this will not be possible until the crystal structure has been determined. Upon cooling, the $9 \mathrm{G}$ room temperature line width of $\mathrm{K}_{\mathrm{H}}-(\mathrm{ET})_{2} \mathrm{Cu}\left(\mathrm{CF}_{3}\right)_{4}(\mathrm{TCE})$ slowly increases to $15 \mathrm{G}$ at $20 \mathrm{~K}$ below which temperature a rapid decrease in line width is observed. [57]

\section{6. $(\mathrm{ET})_{2} \mathrm{Ag}_{\left(\mathrm{CF}_{3}\right)_{2}(\mathrm{CN})_{2}}$}

The crystal structure of $(\mathrm{ET})_{2} \mathrm{Ag}\left(\mathrm{CF}_{3}\right)_{2}(\mathrm{CN})_{2}$ has been determined at $123 \mathrm{~K}$ by $\mathrm{X}$-ray diffraction. The atomic numbering scheme is given in Figure 9 and the atomic coordinates listed in Table 3. A projection of the unit cell on the $b c$-plane is shown in Figure 3, with a comparison to the isostructural (ET) $)_{2} M\left(\mathrm{CF}_{2}\right)_{4}$ salts. $(\mathrm{ET})_{2} \mathrm{Ag}\left(\mathrm{CF}_{3}\right)_{2}(\mathrm{CN})_{2}$ crystallizes in the space group $P 2_{1} / \mathrm{n}$ with lattice parameters $a=$ $4.9662(1) \AA, b=9.3358(2) \AA, c=38.7715(7) \AA, \beta=91.561(1)^{\circ}, V=1796.9(1) \AA^{3}$. Although the $\mathrm{Ag}\left(\mathrm{CF}_{3}\right)_{2}(\mathrm{CN})_{2}^{-}$anion is smaller than $\mathrm{Ag}\left(\mathrm{CF}_{3}\right)_{4}^{-}$, the unit cell of $(\mathrm{ET})_{2} \mathrm{Ag}\left(\mathrm{CF}_{3}\right)_{2}(\mathrm{CN})_{2}$ is expanded along the $b$-axis. This is because the cyano ligands extend about $1.5 \AA$ further in the coordination plane from the metal center than the trifluoromethyl appendages. Because the $\mathrm{Ag}\left(\mathrm{CF}_{3}\right)_{2}(\mathrm{CN})_{2}{ }^{-}$anion is rotated about $35^{\circ}$ from the unit cell axes, the cyano groups push mostly into the ET stacks located \pm 0.5 unit cell along $b$. This displacement in the ET layer causes adjacent ET stacks 
to be more side-to-side and allows for better intermolecular S ...S contacts between the outer $\mathrm{S}$ atoms. In contrast to the room temperature structure of $(\mathrm{ET})_{2} \mathrm{Ag}\left(\mathrm{CF}_{3}\right)_{4}$, both the ethylene groups of the ET molecules in $(\mathrm{ET})_{2} \mathrm{Ag}\left(\mathrm{CF}_{3}\right)_{2}(\mathrm{CN})_{2}$ are ordered at $123 \mathrm{~K}$. A low temperature X-ray structural study will determine whether a similar ethylene-group ordering occurs in the $(\mathrm{ET})_{2} \mathrm{Ag}\left(\mathrm{CF}_{3}\right)_{4}$ salt.

The ac susceptibility of crystals of $(\mathrm{ET})_{2} \mathrm{Ag}\left(\mathrm{CF}_{3}\right)_{2}(\mathrm{CN})_{2}$ was measured to temperatures as low as $1.2 \mathrm{~K}$, with no indication of superconductivity.

\section{7. $\mathrm{K}_{\mathrm{L}}-(\mathrm{ET})_{2} \underline{\mathrm{Ag}}\left(\mathrm{CF}_{3}\right)_{3} \mathrm{Cl}(1,1,2$-trichloroethane $)$}

The x-ray crystal structure of the $\kappa_{\mathrm{L}}-(\mathrm{ET})_{2} \mathrm{Ag}\left(\mathrm{CF}_{3}\right)_{3} \mathrm{Cl}(1,1,2$-trichloroethane) salt was determined at $123 \mathrm{~K}$ and found to be isostructural to the $\kappa_{\mathrm{L}}$ $(\mathrm{ET})_{2} M\left(\mathrm{CF}_{3}\right)_{4}(1,1,2$-trihaloethane) salts. The unit cell parameters were found to be: $a=12.8499(24) \AA, b=37.614(6) \AA, c=8.4711(17) \AA, V=4094.4(1.3) \AA^{3}$. Compared to the $115 \mathrm{~K}$ structure of $\mathrm{K}_{\mathrm{L}}-(\mathrm{ET})_{2} \mathrm{Ag}\left(\mathrm{CF}_{3}\right)_{4}\left(1,1,2\right.$-trichloroethane), the unit cell of $\mathrm{K}_{\mathrm{L}}$ $(\mathrm{ET})_{2} \mathrm{Ag}\left(\mathrm{CF}_{3}\right)_{3} \mathrm{Cl}(1,1,2$-trichloroethane $)$ is contracted along the three crystallographic axes by $0.66 \%, 0.95 \%$, and $0.65 \%$, respectively, resulting in a volume reduction of $2.24 \%$. This smaller unit cell is a direct result of the exchange of a trifluoromethyl group for a chloride ligand.

As illustrated in Figure 4, an even greater degree of disorder is observed in the anion layer of $\kappa_{\mathrm{L}}-(\mathrm{ET})_{2} \mathrm{Ag}\left(\mathrm{CF}_{3}\right)_{3} \mathrm{Cl}\left(1,1,2\right.$-trichloroethane) than was found for $\kappa_{\mathrm{L}}-$ $(\mathrm{ET})_{2} \mathrm{Ag}\left(\mathrm{CF}_{3}\right)_{4}\left(1,1,2 \text {-trichloroethane). As in the } \kappa_{\mathrm{L}} \text {-(ET) }\right)_{2} \mathrm{Ag}\left(\mathrm{CF}_{3}\right)_{4}(1,1,2-$ trichloroethane) structure, the trifluoromethyl groups of $\kappa_{\mathrm{L}}-(\mathrm{ET})_{2} \mathrm{Ag}\left(\mathrm{CF}_{3}\right)_{3} \mathrm{Cl}(1,1,2-$ trichloroethane) were found to be disordered over two conformations. Additionally, the chloride ligand in $\kappa_{\mathrm{L}}-(\mathrm{ET})_{2} \mathrm{Ag}\left(\mathrm{CF}_{3}\right)_{3} \mathrm{Cl}(1,1,2$-trichloroethane) was found to be 
disordered over two sites related by a mirror plane. Thus, two of the coordination sites of the $\mathrm{Ag}\left(\mathrm{CF}_{3}\right)_{3} \mathrm{Cl}^{-}$anion were found to contain only two orientations of the trifluoromethyl group, and the other two sites contained 50\% disordered $\mathrm{CF}_{3}$ groups and $50 \% \mathrm{Cl}$ ligands.

Crystals of $\kappa_{\mathrm{L}}$-(ET) $)_{2} \mathrm{Ag}\left(\mathrm{CF}_{3}\right)_{3} \mathrm{Cl}(1,1,2$-trichloroethane) were examined by ac susceptibility to temperatures as low as $1.2 \mathrm{~K}$. A weak diamagnetic signal was observed below $1.4 \mathrm{~K}$, but the shielding fraction was too low to confirm bulk superconductivity. Thus, the symmetry breaking substitution of one $\mathrm{Cl}$ atom for one of the $\mathrm{CF}_{3}$ groups radically alters the ground state property of this salt and significantly depresses, or destroys, the superconducting ground state.

\section{8. $\mathrm{K}_{\mathrm{L}}$-(BEDT-TSF $)_{2} \mathrm{Ag}\left(\mathrm{CF}_{3}\right)_{4}(1,1,2$-trichloroethane $)$}

Crystals of the $\kappa_{\mathrm{L}}$-(BEDT-TSF $)_{2} \mathrm{Ag}\left(\mathrm{CF}_{3}\right)_{4}(1,1,2$-trichloroethane) salt were prepared by a method analogous to that used for the ET salt. This salt grows as tiny black blocks. Very thin needle-like crystals have also been grown, which may be isostructural to the $\kappa_{\mathrm{H}}$-phase. To date, no crystals of the solvent-free phase have been identified. Identification of the various phases of the BEDT-TSF salt through ESR spectroscopy has not been possible because of the much broadened ESR line width compared to ET.

X-ray diffraction measurements indicated that $\kappa_{\mathrm{L}}$-(BEDTTSF $)_{2} \mathrm{Ag}\left(\mathrm{CF}_{3}\right)_{4}(1,1,2$-trichloroethane) crystallizes in the orthorhombic space group Pnma and is essentially isostructural to the $2.4 \mathrm{~K}$ superconductor $\kappa_{\mathrm{L}}$ $(\mathrm{ET})_{2} \mathrm{Ag}\left(\mathrm{CF}_{3}\right)_{4}(1,1,2$-trichloroethane). However, the four selenium atoms in the BEDT-TSF molecule result in a $3.5 \%$ increase in the unit cell volume. At room 
temperature, the unit cell parameters for $\kappa_{\mathrm{L}}$-(BEDT-TSF) $\mathrm{Ag}\left(\mathrm{CF}_{3}\right)_{4}(1,1,2-$ trichloroethane) were found to be: $a=13.155(1), b=39.333(2), c=8.6479(4) \AA$, and $V=4474.6(5) \AA^{3}$. The crystal structure of $\kappa_{\mathrm{L}}$-(BEDT-TSF $)_{2} \mathrm{Ag}\left(\mathrm{CF}_{3}\right)_{4}(1,1,2-$ trichloroethane) is illustrated in Figure 10 as a projection on the $a b$-plane. The atomic numbering scheme is given in Figure 11 and the atomic coordinates listed in Table 3. The $a$-axis for the BEDT-TSF salt is $0.020 \AA(0.2 \%)$ shorter than in the ET salt, while the $b$ and $c$ axes increase by $1.159 \AA$ (3\%) and $0.053 \AA(0.6 \%)$, respectively. Thus, the area of the unit cell in the ac plane is only slightly (0.5\%) larger in the selenium containing salt. The increase in unit cell volume is mostly due to an expansion along the $b$-axis: a direct result of the greater length of the BEDT-TSF molecule. These results are similar to that observed for the isostructural ET and BEDT-TSF salts of $\mathrm{Cu}\left[\mathrm{N}(\mathrm{CN})_{2}\right] \mathrm{Br}^{-}$. [78]

In contrast to $\kappa_{\mathrm{L}}-(\mathrm{ET})_{2} \mathrm{Ag}\left(\mathrm{CF}_{3}\right)_{4}(1,1,2$-trichloroethane), we have observed no indication of superconductivity in $\kappa_{\mathrm{L}}$-(BEDT-TSF $)_{2} \mathrm{Ag}\left(\mathrm{CF}_{3}\right)_{4}(1,1,2$-trichloroethane) to temperatures as low as $1.2 \mathrm{~K}$. One of the ethylene groups in $\kappa_{\mathrm{L}}$-(BEDT$\mathrm{TSF})_{2} \mathrm{Ag}\left(\mathrm{CF}_{3}\right)_{4}(1,1,2$-trichloroethane) is disordered at room temperature with approximately $2 / 3$ of the groups in the eclipsed conformation. In the case of the $\mathrm{Cu}$ $\left[\mathrm{N}(\mathrm{CN})_{2}\right] \mathrm{Br}^{-}$salts of ET and BEDT-TSF, the lack of superconductivity in the $\kappa(\mathrm{BEDT}-\mathrm{TSF})_{2} \mathrm{Cu}\left[\mathrm{N}(\mathrm{CN})_{2}\right] \mathrm{Br}$ salt was rationalized [78] from the crystallographic disorder of the ethylene end groups, even at $20 \mathrm{~K}$, compared to ordered end groups in the ET salt below at least $125 \mathrm{~K}$. [65] Whether this is the case in the $\mathrm{Ag}\left(\mathrm{CF}_{3}\right)_{4}^{-}$ salts will require low temperature structural data. The selenium substitution in $\kappa_{\mathrm{L}}$ (BEDT-TSF) $)_{2} \mathrm{Ag}\left(\mathrm{CF}_{3}\right)_{4}(1,1,2$-trichloroethane) would be expected to broaden the electronic bandwidth and thus decrease the density of states at the Fermi level. Although this would be expected to decrease the superconducting transition 
temperature, it is unlikely that this alone would account for the lack of superconductivity above $1.2 \mathrm{~K}$.

\section{9. $\mathrm{Cu}\left(\mathrm{CF}_{2} \mathrm{H}_{1}\right)^{-}$Salts of ET}

Through an electrolyte substitution of PPN $\left[\mathrm{Cu}\left(\mathrm{CF}_{2} \mathrm{H}\right)_{4}\right]$ for PPN $\left[\mathrm{Cu}\left(\mathrm{CF}_{3}\right)_{4}\right]$ during the electrocrystallization process, we have attempted to prepare an $\mathrm{Cu}\left(\mathrm{CF}_{2} \mathrm{H}\right)_{4}^{-}$salt with ET through methods described above. Although a variety of crystallization solvents, including TCE, TCE/EtOH, 1,2-dibromo-1-chloroethane, 1bromo-2,2-dichloroethane, 1,2-dichloro-1-bromoethane, and THF, were tried, only tiny shards of irregular crystals grew. No superconductivity was observed in these black microcrystals, and the crystals were not of sufficient quality for crystal structure determination. It is interesting to note that substitution of $\mathrm{CF}_{2} \mathrm{H}$ ligands for $\mathrm{CF}_{3}$ groups has significant impact on the crystal growth and apparently prevents the $\kappa_{\mathrm{L}}$-(ET) $)_{2} M\left(\mathrm{CF}_{3}\right)_{4}(1,1,2$-trihaloethane) phase from forming. This suggests that the $\mathrm{CF}_{3} / \mathrm{ET}$ interactions may provide important stabilizing forces for the stabilization of ET salts containing trifluoromethyl-based anions. Experiments are in progress to prepare higher quality crystals of an ET salt containing the $\mathrm{Cu}\left(\mathrm{CF}_{2} \mathrm{H}\right)_{4}^{-}$anion.

\subsection{0. $\mathrm{Cu}\left(\mathrm{CF}_{2} \mathrm{CF}_{3}\right)_{4}^{-}$Salts of ET}

Through substitution of PPN $\left[\mathrm{Cu}\left(\mathrm{CF}_{2} \mathrm{CF}_{3}\right)_{4}\right]$ for PPN $\left[\mathrm{Cu}\left(\mathrm{CF}_{3}\right)_{4}\right]$ in the electrochemical cell, we have grown crystals of ET $\left[\mathrm{Cu}\left(\mathrm{CF}_{2} \mathrm{CF}_{3}\right)_{4}\right]_{x}$. Poor quality crystals were grown when 1,1,2-tribromoethane or methylene chloride were used as the crystallization solvent, but small plate-like crystals were grown in TCE and chlorobenzene. These plate-like crystals had an ESR line width between 38 and $46 \mathrm{G}$. Ac susceptibility measurements indicate that these crystals do not 
superconduct above $1.2 \mathrm{~K}$. It is expected that the larger $-\mathrm{CF}_{2} \mathrm{CF}_{3}$ ligands will significantly affect the solid state structure of these crystals. A more thorough study of the structure and physical properties of these crystals is in progress.

\subsection{Trifluoromethyl metallate anion structural comparison}

The trifluoromethyl groups of the $\mathrm{Cu}\left(\mathrm{CF}_{3}\right)_{4}^{-}$anion in the PPN $\left[\mathrm{Cu}\left(\mathrm{CF}_{3}\right)_{4}\right]$ salt have been found to be ordered with the neighboring groups staggered and the trans groups eclipsed. [46] The $\mathrm{CuC}_{4}$ core is nearly planar, with the trans $\mathrm{C}-\mathrm{Cu}-\mathrm{C}$ bond angles $165^{\circ}$ and $172^{\circ}$. The slight non-planarity is probably a result of steric interactions of the $\mathrm{CF}_{3}$ groups and intermolecular packing forces. Ordered $M\left(\mathrm{CF}_{3}\right)_{4}^{-}$ anions are also present in the $(\mathrm{ET})_{2} M\left(\mathrm{CF}_{3}\right)_{4}(M=\mathrm{Ag}, \mathrm{Au})$ salts. However, in these salts, the trifluoromethyl groups are each rotated about $30^{\circ}$ in the same direction, thus placing the trans groups in a staggered conformation. Because the metal center lies on an inversion center, the trans C-M-C bonds are required, by symmetry, to be linear. The cis-C-Ag-C bonds are $89.8(2)^{\circ}$. The $M-\mathrm{C}$ bonds are slightly longer in $(\mathrm{ET})_{2} \mathrm{Ag}\left(\mathrm{CF}_{3}\right)_{4}(2.106$ and $2.096 \AA)$ than in $(\mathrm{ET})_{2} \mathrm{Au}\left(\mathrm{CF}_{3}\right)_{4}(2.067$ and $2.087 \AA$ ).

The $M\left(\mathrm{CF}_{3}\right)_{4}^{-}$anions in the $\kappa_{\mathrm{L}}-(\mathrm{ET})_{2} M\left(\mathrm{CF}_{3}\right)_{4}(1,1,2$-trihaloethane $), \kappa_{\mathrm{L}}{ }^{-}$ $(\mathrm{ET})_{2} M\left(\mathrm{CF}_{3}\right)_{4}\left(1,1,2 \text {-trihaloethane), and } \kappa_{\mathrm{L}} \text {-(BEDT-TSF) }\right)_{2} M\left(\mathrm{CF}_{3}\right)_{4}(1,1,2$-trihaloethane) salts are very similar to each other. There is significant disorder of the trifluoromethyl groups, indicating twisting around the $M-\mathrm{C}$ bonds. In these salts, the anion lies on a mirror plane which bisects the C-M-C angle. Two of the trifluoromethyl carbon positions are fully occupied, but because of the slight nonplanarity of the $M \mathrm{C}_{4}$ core, the remaining two mirror-symmetric carbon atoms partially occupy two sites $0.44 \AA$ apart. The fluorine atoms on adjacent 
trifluoromethyl groups cannot be related by a mirror plane because simultaneous occupation of mirror-symmetric fluorine sites would result in steric interactions. Thus, adjacent trifluoromethyl groups must alternately occupy sites unrelated by symmetry. The $M$-C distances in the $\mathrm{K}_{\mathrm{L}}-(\mathrm{ET})_{2} M\left(\mathrm{CF}_{3}\right)_{4}$ (1,1,2-trihaloethane) $(M=\mathrm{Cu}$, $\mathrm{Ag}$ ) salts are: $1.94,1.96,1.99 \AA(\mathrm{Cu})$ and $2.09,2.09,2.11 \AA(\mathrm{Ag})$. The trans-C-Cu-C bond angles are 169.5 and $172.9^{\circ}$ and the trans-C-Ag-C bond angles are 173.0 and $174.8^{\circ}$.

The $(\mathrm{ET})_{2}\left[\right.$ trans- $\left.\mathrm{Ag}\left(\mathrm{CF}_{3}\right)_{2}(\mathrm{CN})_{2}\right]$ salt is only the second structural determination of the $\left[\text { trans- } \mathrm{Ag}\left(\mathrm{CF}_{3}\right)_{2}(\mathrm{CN})_{2}\right]^{-}$anion, and the first to contain ordered trifluoromethyl groups. The structure of the $\left[\mathrm{PPh}_{4}\right]\left[\right.$ trans- $\left.\mathrm{Ag}\left(\mathrm{CF}_{3}\right)_{2}(\mathrm{CN})_{2}\right]$ salt has previously been reported to contain disordered $\mathrm{CF}_{3}$ groups. [55] The $\mathrm{Ag}-\mathrm{CF}_{3}$ and Ag-CN bond lengths of $2.103 \AA$ and $2.010 \AA$ are virtually identical to those found in the $\mathrm{PPh}_{4}{ }^{+}$salt. The $\mathrm{AgC}_{4}$ core is nearly planar, with the trans ligands related by an inversion center, and the NC-Ag-CF bond angle $89.88^{\circ}$. Due to the lanthanide contraction, the Ag-CN bond length is also essentially the same as the $\mathrm{Au}-\mathrm{CN}$ bond length observed in the $(\mathrm{ET})_{2}\left[\right.$ trans- $\left.\mathrm{Au}(\mathrm{CN})_{2} \mathrm{Cl}_{2}\right]$ salt $(2.02 \AA)$. [26] The C-F bond lengths in $(\mathrm{ET})_{2} \mathrm{Ag}\left(\mathrm{CF}_{3}\right)_{2}(\mathrm{CN})_{2}$ range from $1.315 \AA-1.340 \AA$.

\section{Conclusions}

The beauty of utilizing large, discrete anions is that these anions can be finetuned by the synthetic chemist to probe how minor structural changes affect the superconducting state. There are a very limited number of ways that simple anions such as $\mathrm{PF}_{6}^{-}, \mathrm{ClO}_{4}^{-}, \mathrm{I}_{3}^{-}$, etc. can be chemically modified. Derivatives of polymeric anions such as $\mathrm{Cu}\left(\mathrm{SCN}_{2}\right)^{-}, \mathrm{Cu}\left[\mathrm{N}(\mathrm{CN})_{2}\right] \mathrm{Br}^{-}$, etc. are nearly impossible to synthesize by design. However, with large, discrete organometallic anions, such as those 
related to $M\left(\mathrm{CF}_{3}\right)_{4}^{-}$, a large number of similar anions can be rationally devised and synthesized. As structure/property relationships are developed for the $x$ (ET) $)_{2} M\left(\mathrm{CF}_{3}\right)_{4}(1,1,2$-trihaloethane) family, the importance of the different packing motifs on superconductivity may be elucidated.

It seems that the $\mathrm{K}$-(ET) $)_{2} M\left(\mathrm{CF}_{3}\right)_{4}(1,1,2$-trihaloethane) structural type should support higher superconducting transition temperatures if larger, related anions or solvent molecules could be cocrystallized into this structural motif. Once again, the obstacle to higher $T_{\mathrm{c}} \mathrm{s}$ appears not to be the ET molecule or the packing motif, but rather limitations in synthesizing molecules that will pack in the desired structure. Thus, we hope to achieve higher $T_{\mathrm{c}} \mathrm{s}$ in organic systems through the use of larger anions which will form thick insulating layers. The more functional groups that the components of organic superconductors have, the greater the prospects are for preparing families of superconducting salts with large numbers of members and higher $T_{\mathrm{c}} \mathrm{s}$.

Other research groups have also recently taken advantage of large, discrete anions for the synthesis of superconducting salts. The $\mathrm{Fe}\left(\mathrm{C}_{2} \mathrm{O}_{4}\right)_{3}{ }^{3-}$ anion has been combined with ET to form crystals of $\beta$ "-(ET) $)_{4}\left[\left(\mathrm{H}_{2} \mathrm{O}\right) \mathrm{Fe}\left(\mathrm{C}_{2} \mathrm{O}_{4}\right)_{3}\right] \mathrm{PhCN}$ which has a superconducting transition temperature near $8.5 \mathrm{~K}$. [79] In this system, it should be possible to prepare isostructural salts and tune the physical properties via modification of three components: $\mathrm{Fe}\left(\mathrm{C}_{2} \mathrm{O}_{4}\right)_{3}{ }^{3-}, \mathrm{H}_{2} \mathrm{O}$, and $\mathrm{PhCN}$. It has already been shown that the first of these, $\mathrm{Fe}\left(\mathrm{C}_{2} \mathrm{O}_{4}\right)_{3}{ }^{3-}$, can be replaced with the $\mathrm{Cr}\left(\mathrm{C}_{2} \mathrm{O}_{4}\right)_{3}{ }^{3-}$ to yield the superconducting $\beta^{\prime \prime}-(\mathrm{ET})_{4}\left[\left(\mathrm{H}_{2} \mathrm{O}\right) \mathrm{Cr}\left(\mathrm{C}_{2} \mathrm{O}_{4}\right)_{3}\right] \mathrm{PhCN}\left(T_{\mathrm{c}}=6.0 \mathrm{~K}\right)$. [80] The second of these, $\mathrm{H}_{2} \mathrm{O}$, can be replaced by $\mathrm{K}^{+}$or $\mathrm{NH}_{4}^{+}$. [81] However, the replacement of a neutral molecule with a monopositive cation changes the band filling and drastically alters the packing of the ET molecules, thus destroying the 
superconducting state. More recently, a report of a superconducting salt, (ET) $\mathrm{K}$ $\left[\mathrm{Fe}(\mathrm{CN})_{5} \mathrm{NO}_{2}\right.$, containing the nitroprusside anion has appeared. [82] Again, structure/property modification should be possible through exchange of the cocrystallized alkali metal cation, the metal, or the anion's ligands.

The continuing discovery of a rapidly growing number of organic superconductors demonstrates that organic superconductivity is a widespread phenomenon, with vast possibilities for the synthesis of a wide range of materials, some of which will undoubtedly have increased $T_{\mathrm{c}} \mathrm{s}$ above present levels. In order to develop new and improved superconducting materials, it will be crucial to better understand the charge-pairing mechanisms by which superconductivity occurs. To develop this understanding, the similarities between organic and cuprate superconductors must be considered. As an example, both have layered crystal structures and exhibit a competition between insulating and superconducting ground states, highly anisotropic electrical and magnetic properties, and both require very large magnetic fields to completely suppress the superconducting state. Similarities abound between these two classes. It would seem that ultimately, as more of the important characteristics of the superconducting state are realized, the vast synthetic capabilities of organic chemists will be called upon to tailor make molecules that contain the structural and chemical features required to produce charge transfer salts possessing desired properties. Because of the structural similarities and anisotropic nature between the organic superconductors and the high $T_{\mathrm{c}}$ cuprates, there is much hope that very high $T_{c} \mathrm{~s}(>100 \mathrm{~K})$ will someday be achieved in organic materials. 


\section{Acknowledgments}

Work at Argonne National Laboratory was supported by the US Department of Energy, Office of Basic Energy Sciences, Division of Materials Sciences, under contract No. W-31-109-ENG-38 at ANL. Research at the University of Cologne was supported by the Fonds der Chemischen Industrie and the Ministerium für Wissenschaft und Forschung des Landes Nordrhein-Westfalen (Arbeitsgemeinschaft Fluorchemie). Work at University of Wuppertal was supported by the Deutsche Forschungsgemeinschaft and the Fonds der Chemischen Industrie. 


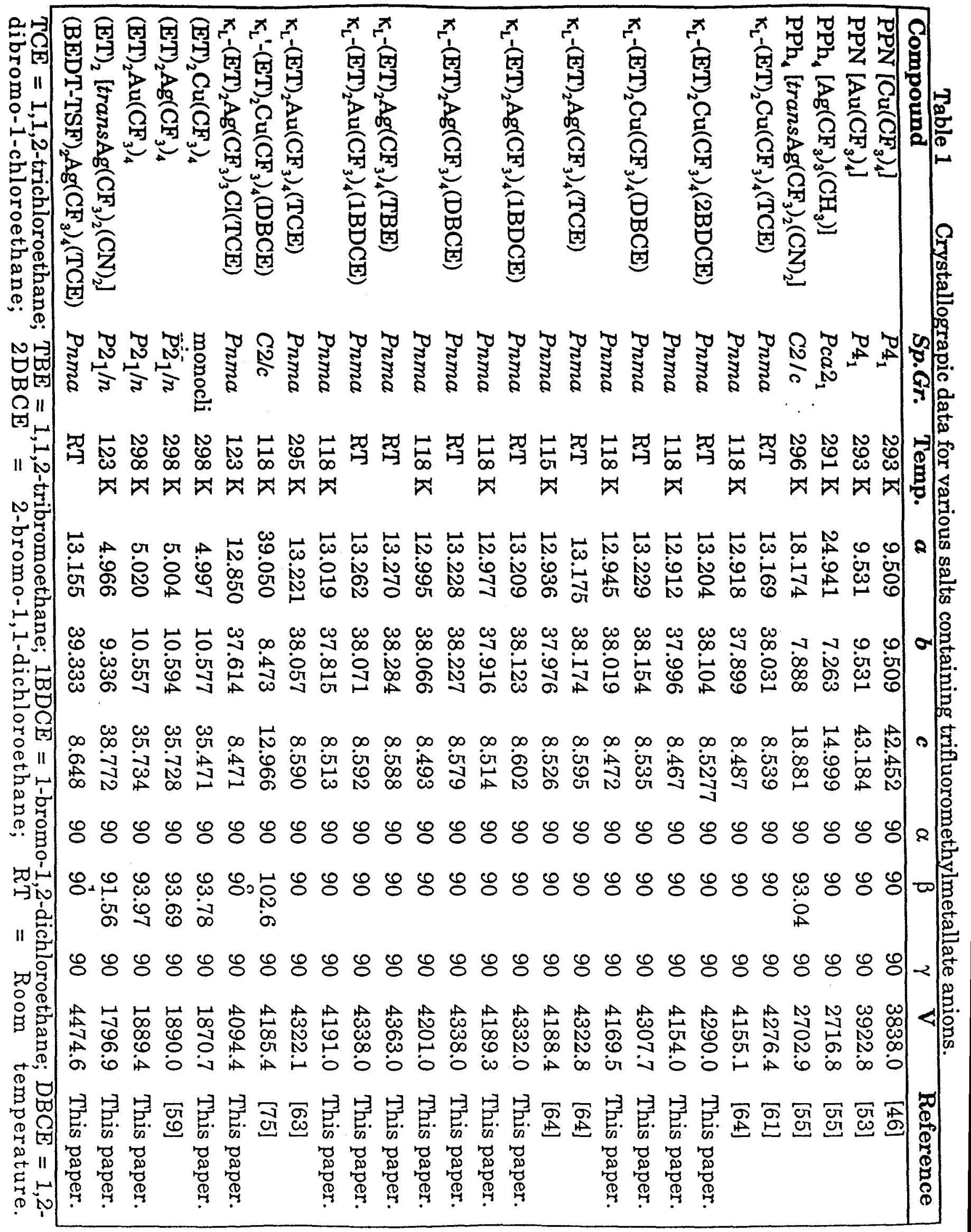




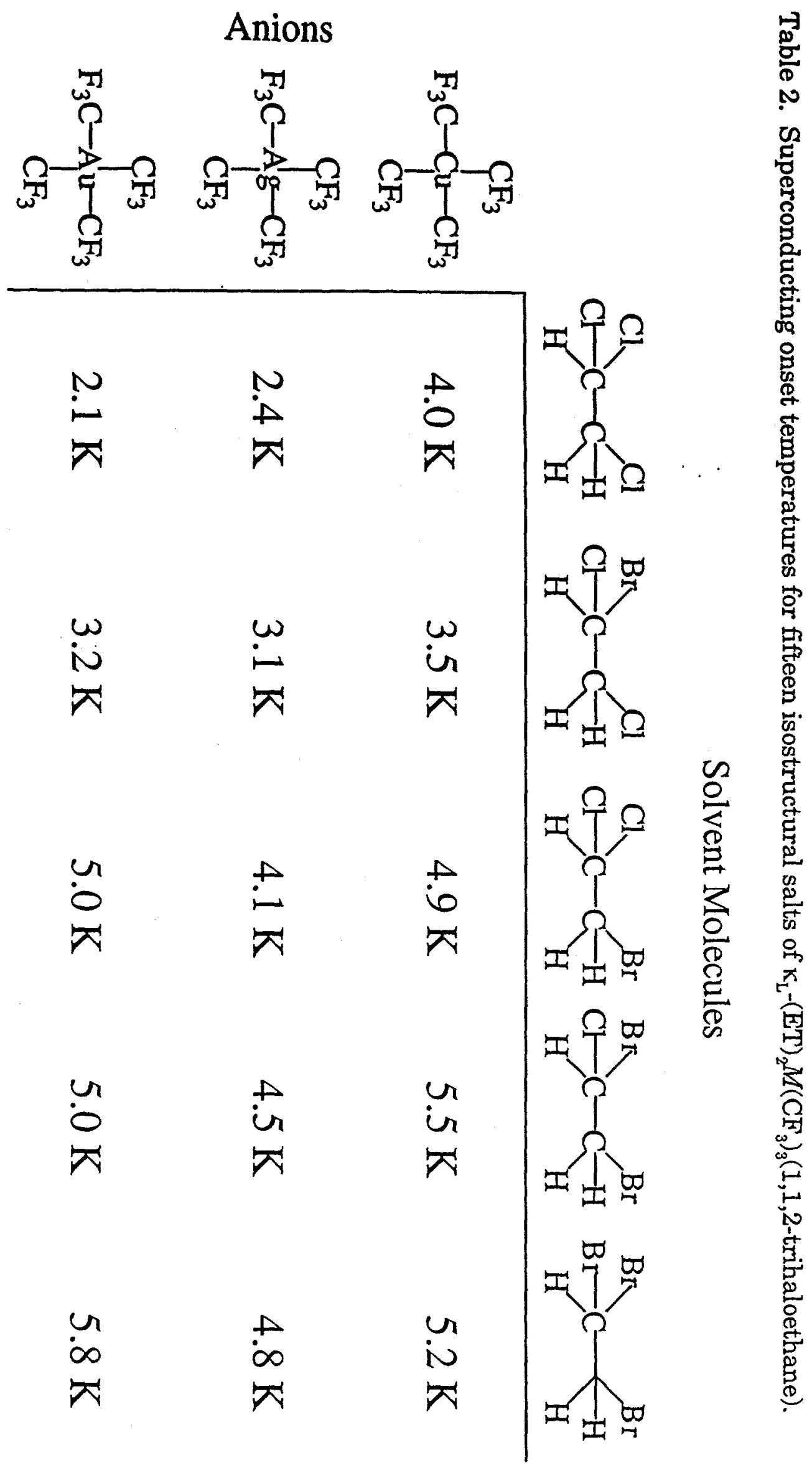


Table 3. Fractional atomic coordinates and equivalent isotropic thermal parameters $\left(\AA^{2}\right)$ in $(\mathrm{ET})_{2} \mathrm{Ag}\left(\mathrm{CF}_{3}\right)_{2}(\mathrm{CN})_{2}$.

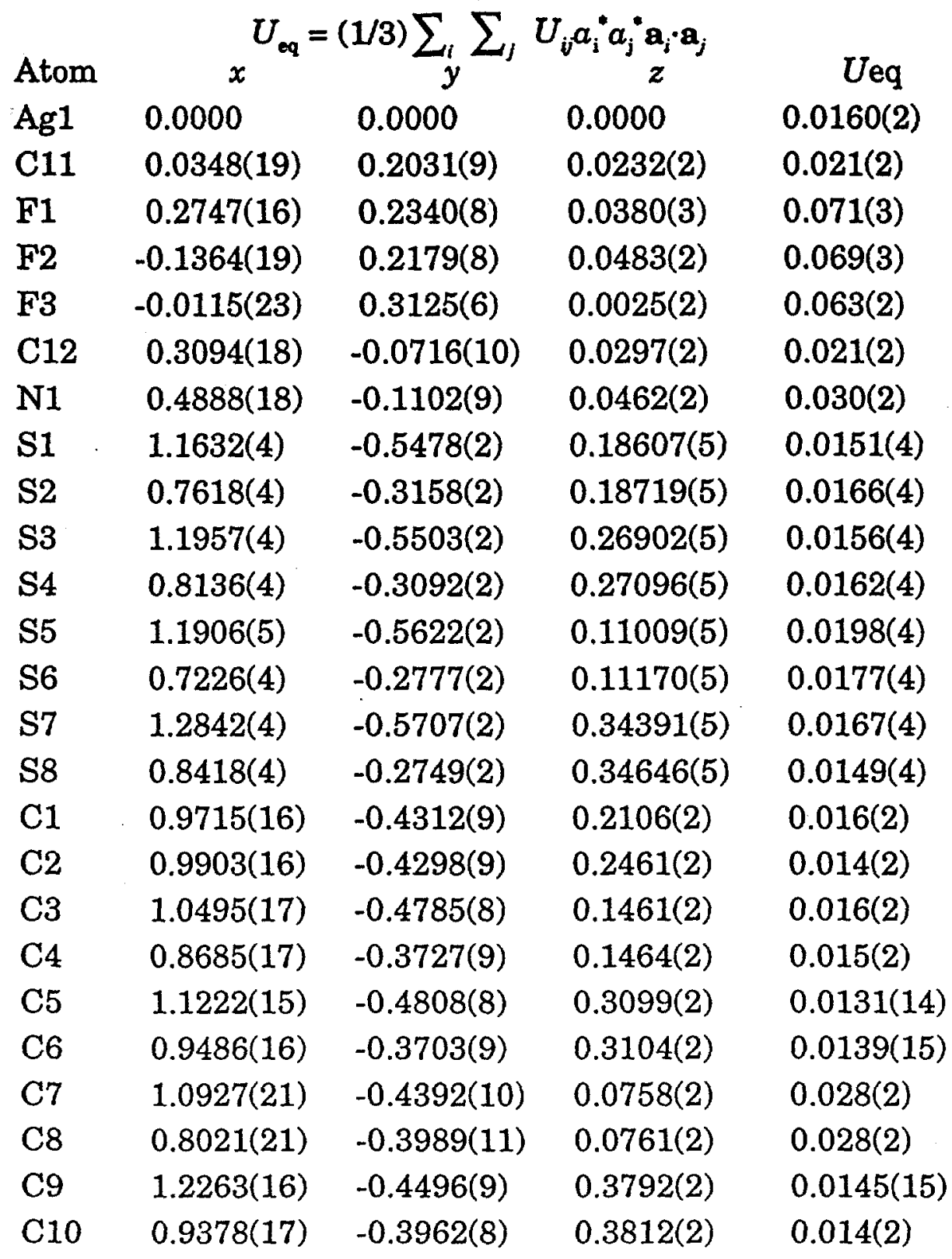


Table 4. Fractional atomic coordinates and equivalent isotropic thermal parameters $\left(\AA^{2}\right)$ in $\mathrm{K}_{\mathrm{L}}-(\mathrm{BEDT}-\mathrm{TSF})_{2} \mathrm{Ag}\left(\mathrm{CF}_{3}\right)_{4}$ (TCE).

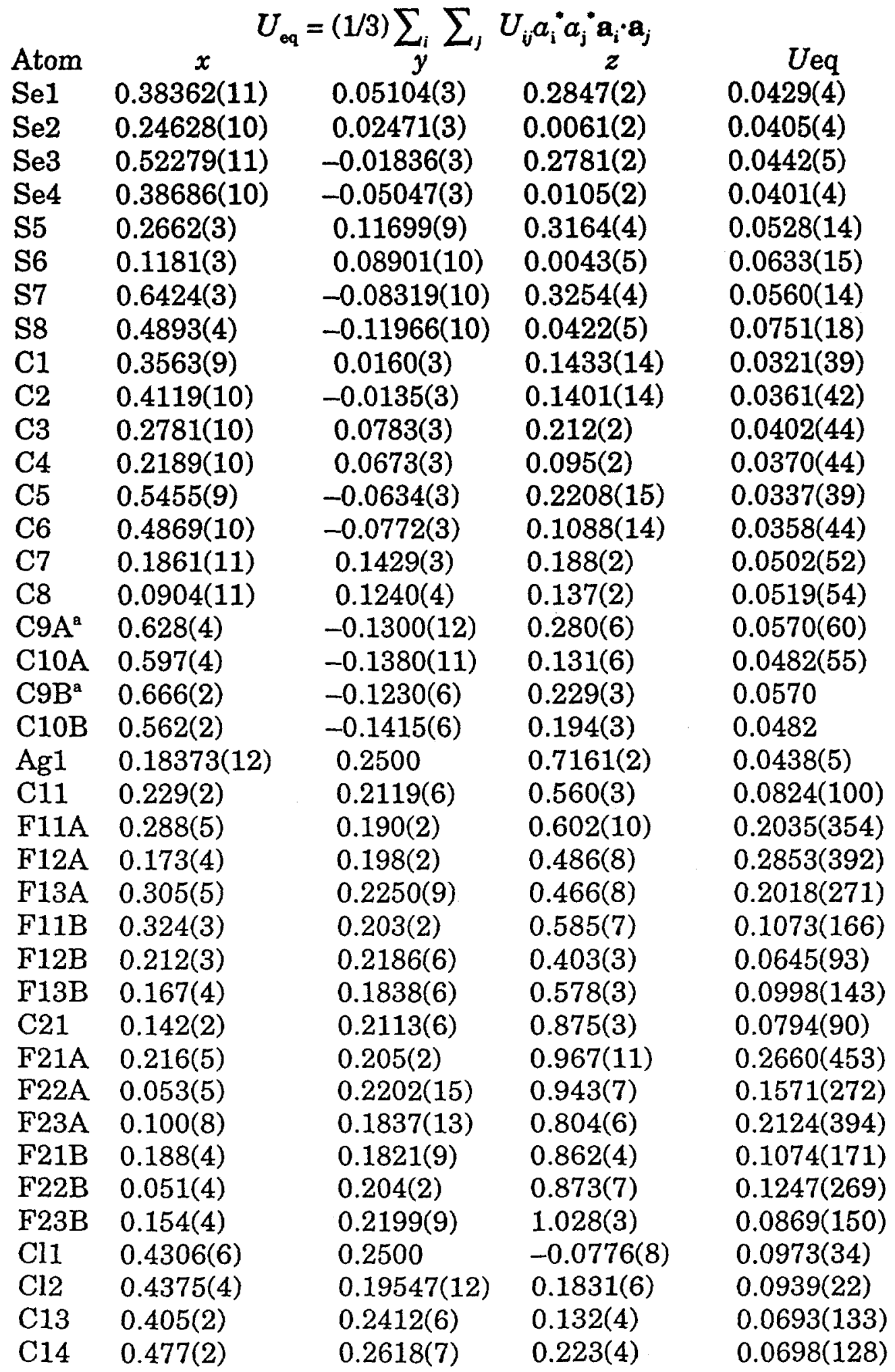




\section{References}

[1] H. Akamatu, H. Inokuchi, Y. Matsunaga, Nature 173 (1954) 168.

[2] J. Ferraris, D. O. Cowan, V. J. Walatka, J. H. Perlstein, J. Am. Chem. Soc. 95 (1973) 948.

[3] L. B. Coleman, M. J. Cohen, D. J. Sandman, F. G. Yamagishi, A. F. Garito, A. J. Heeger, Solid State Commun. 12 (1973) 1125.

[4] D. Jérome, A. Mazaud, M. Ribault, K. Bechgaard, J. Phys. Lett. 41 (1980) L95.

[5] J. M. Williams, J. R. Ferraro, R. J. Thorn, K. D. Carlson, U. Geiser, H. H. Wang, A. M. Kini, M. H. Whangbo In Prentice Hall: Englewood Cliffs, New Jersey, $1992 ; \mathrm{pp}$.

[6] M. Tokumoto, H. Bando, K. Murata, H. Anzai, N. Kinoshita, K. Kajimura, T. Ishiguro, G. Saito, Synth. Met. 13 (1986) 9.

[7] H. Urayama, H. Yamochi, G. Saito, K. Nozawa, T. Sugano, M. Kinoshita, S. Sato, K. Oshima, A. Kawamoto, J. Tanaka, Chem. Lett. (1988) 55.

[8] A. M. Kini, U. Geiser, H. H. Wang, K. D. Carlson, J. M. Williams, W. K. Kwok, K. G. Vandervoort, J. E. Thompson, D. L. Stupka, D. Jung, M.-H. Whangbo, Inorg. Chem. 29 (1990) 2555. 
[9] J. M. Williams, A. M. Kini, H. H. Wang, K. D. Carlson, U. Geiser, L. K. Montgomery, G. J. Pyrka, D. M. Watkins, J. M. Kommers, S. J. Boryschuk, A. V. Strieby Crouch, W. K. Kwok, J. E. Schirber, D. L. Overmyer, D. Jung, M.-H. Whangbo, Inorg. Chem. 29 (1990) 3272.

[10] H. H. Wang, K. D. Carlson, U. Geiser, A. M. Kini, A. J. Schultz, J. M. Williams, L. K. Montgomery, W. K. Kwok, K. G. Welp, K. G. Vandervoort, S. J. Boryschuk, A. V. Strieby Crouch, J. M. Kommers, D. M. Watkins, J. E. Schirber, D. L. Overmyer, D. Jung, J. J. Novoa, M.-H. Whangbo, Synth. Met. 41-43 (1991) 1983.

[11] H. H. Wang, A. M. Kini, L. K. Montgomery, U. Geiser, K. D. Carlson, J. M. Williams, J. E. Thompson, D. M. Watkins, W. K. Kwok, U. Welp, K. G. Vandervoort, Chem. Mater. 2 (1990) 482.

[12] U. Geiser, H. H. Wang, K. D. Carlson, J. M. Williams, H. A. J. Charlier, J. E. Heindl, G. A. Yaconi, B. J. Love, M. W. Lathrop, J. E. Schirber, D. L. Overmyer, J. Ren, M.-H. Whangbo, Inorg. Chem. 30 (1991) 2586.

[13] H. Yamochi, T. Nakamura, T. Komatsu, N. Matsukawa, T. Inoue, G. Saito, T. Mori, M. Kusunoki, K.-i. Sakaguchi, Solid State Commun. 82 (1992) 101.

[14] A. Kawamoto, J. Tanaka, M. Tanaka, Acta Cryst. C43 (1987) 205.

[15] U. Geiser, H. H. Wang, C. E. Hammond, M. A. Firestone, M. A. Beno, K. D. Carlson, L. Nunez, J. M. Williams, Acta Cryst. C43 (1987) 656. 
[16] X. Bu, P. Coppens, B. Lederle, M. J. Naughton, Acta Cryst. C 47 (1991) 2082.

[17] M. B. Inoue, M. Inoue, M. A. Bruck, Q. Fernando, J. Chem. Soc., Chem. Commun. (1992) 515.

[18] S. V. Konovalikhin, O. A. D'yachenko, A. B. Zolotoi, V. V. Gritsenko, L. O. Atovmyan, E. E. Laukhina, Izv. Acad. Sci. SSSR Ser. Khim (1991) 811.

[19] R. P. Shibaeva, R. M. Lobkovskaya In Kristallografiya; 1988; pp 408-412.

[20] P. Guionneau, G. Bravic, J. Gaultier, D. Chasseau, M. Kurmoo, D. Kanazawa, P. Day, Acta Cryst. (1994) 1894.

[21] S. Hebrard, G. Bravic, J. Gaultier, D. Chasseau, Acta Cryst. C 50 (1994) 1892.

[22] L. I. Buravov, A. V. Gudenko, V. B. Ginodman, A. V. Zvarykina, V. E. Korotkov, N. D. Kushch, L. P. Rozenberg, A. G. Khomenko, R. P. Shibaeva, É. B. Yagubskii In Izv. Akad. Nauk SSSR, Ser. Khim.; 1990; pp 223-224.

[23] P. Wang, S. Bandow, Y. Maruyama, X. Wang, D. Zhu, Synth. Met. 44 (1991) 147.

[24] H. Mori, I. Hirabayashi, S. Tanaka, T. Mori, H. Inokuchi, Solid State Commun. 76 (1990) 35. 
[25] H. H. Wang, M. A. Beno, U. Geiser, M. A. Firestone, K. S. Webb, L. Nuñez, G. W. Crabtree, K. D. Carlson, J. M. Williams, L. J. Azevedo, J. F. Kwak, J. E. Schirber, Inorg. Chem. 24 (1985) 2465.

[26] U. Geiser, B. A. Anderson, A. Murray, C. M. Pipan, C. A. Rohl, B. A. Vogt, H. H. Wang, J. M. Williams, D. B. Kang, M. H. Whangbo, Mol. Cryst. Liq. Cryst. 181 (1990) 105.

[27] J. D. Martin, E. Canadell, C. Fitzmaurice, A. M. Z. Slawin, D. J. Williams, J. D. Woollins, J. Chem. Soc. Dalton Trans. (1994) 1995.

[28] L. C. Porter, H. H. Wang, M. A. Beno, K. D. Carlson, C. M. Pipan, R. B. Proksch, J. M. Williams, Solid State Commun. 64 (1987) 387.

[29] T. Mori, H. Inokuchi, Chem. Lett. (1986) 2069.

[30] M. J. Matos, I. C. Santos, R. T. Henriques, M. T. Duarte, Synth. Met. 41-43 (1991) 2155.

[31] C. Bellitto, V. Fares, F. Federici, P. Serino, P. Day, M. Kurmoo, Synth. Met. 79 (1996) 33.

[32] H. Tanaka, A. Kobayashi, H. Kobayashi, Bull. Chem. Soc. Jpn. 70 (1997) 3137. 
[33] J. A. Schlueter, U. Geiser, H. H. Wang, M. L. Van Zile, S. B. Fox, J. M. Williams, A. Laguna, M. Laguna, D. Naumann, T. Roy, Inorg. Chem. 36 (1997) 4265 .

D. Chasseau, D. Watkin, M. J. Rosseinsky, M. Kurmoo, D. R. Talman, P. Day, Synth. Met. 24 (1988) 117.

[35] H. H. Wang, U. Geiser, M. E. Kelly, M. L. Vanzile, A. J. Skulan, J. M. Williams, J. A. Schlueter, A. M. Kini, S. A. Sirchio, L. K. Montgomery, Mol. Cryst. Liq. Cryst. 284 (1996) 427.

A. M. Kini, H. H. Wang, J. A. Schlueter, J. D. Dudek, S. A. Sirchio, K. D. Carlson, J. M. Williams, Physica C (1996) 81. Hosoito, J. Phys. Soc. Jpn. 60 (1991) 3230.

[38] K. Oshima, H. Urayama, H. Yamochi, G. Saito, Synth. Met. 27 (1988) A473.

[39] K. Oshima, H. Urayama, H. Yamochi, G. Saito, J. Phys. Soc. Jpn. 57 (1988) 730.

[40] D. Schweitzer, K. Polychroniadis, T. Klutz, H. J. Keller, I. Hennig, I. Heinen, U. Haeberlen, E. Gogu, S. Gärtner, Synth. Met. 27 (1988) A465. 
[41] G. Saito, H. Yamochi, T. Nakamura, T. Komatsu, T. Ishiguro, Y. Nogami, Y. Ito, H. Mori, K. Oshima, M. Nakashima, S. Uchida, H. Takagi, S. Kagoshima, T. Osada, Synth. Met. 41-43 (1991) 1993.

[42] C. Garrigou-Lagrange, R. Swietlik, C. Sourisseau, P. Delhaes, B. Hilti, J. Zambounis, C. W. Mayer, Mol. Cryst. Liq. Cryst. 229 (1993) 129.

[43] K. Bechgaard, K. Carneiro, F. B. Rasumssen, M. Olsen, G. Rindorf, C. S. Jacobsen, H. J. Pedersen, J. C. Scott, J. Am. Chem. Soc. 103 (1981) 2440.

[44] J. P. Pouget, G. Shirane, K. Bechgaard, J. M. Fabre, Phys. Rev. B 27 (1983) 5203.

T. J. Emge, H. H. Wang, M. A. Beno, P. C. W. Leung, M. A. Firestone, H. C. Jenkins, J. D. Cook, K. D. Carlson, J. M. Williams, E. L. Venturini, L. J. Azevedo, J. E. Schirber, Inorg. Chem. 24 (1985) 1736.

[46] D. Naumann, T. Roy, K.-F. Tebbe, W. Crump, Angew. Chem. Int. Ed. Engl. 32 (1993) 1482.

[47] M. Mizuno, A. F. Garito, M. P. Cava, J. Chem. Soc., Chem. Commun. (1978) 18.

[48] P. E. Reed, J. M. Braam, L. M. Sowa, R. A. Barkhau, G. S. Blackman, D. D. Cox, G. A. Ball, H. H. Wang, J. M. Williams, Inorg. Synth. 26 (1989) 388. 
[49] G. Steimecke, H.-J. Sieler, R. Kirmse, E. Hoyer, Phosphorus and Sulfur 7 (1979) 49.

[50] K. S. Varma, A. Bury, N. J. Harris, A. E. Underhill, Synthesis (1987) 837.

[51] R. Kato, H. Kobayashi, A. Kobayashi, Synth. Met. 41-43 (1991) 2093.

[52] W. Dukat, D. Naumann, Revue de Chimie Minerale 23 (1986) 589.

[53] T. Roy, (1995) Unpublished results.

[54] R. Eujen, B. Hoge, D. J. Brauer, J. Organomet. Chem. 519 (1996) 7.

[55] R. Eujen, B. Hoge, D. J. Brauer, Inorg. Chem. 1997 (1997) 1464.

[56] J. A. Schlueter, J. M. Williams, U. Geiser, J. D. Dudek, M. E. Kelly, S. A. Sirchio, K. D. Carlson, D. Naumann, T. Roy, C. F. Campana, Adv. Mater. 7 (1995) 634.

[57] H. H. Wang, J. A. Schlueter, U. Geiser, J. M. Williams, D. Naumann, T. Roy, Inorg. Chem. 34 (1995) 5552.

[58]

H. H. Wang, M. L. VanZile, U. Geiser, J. A. Schlueter, J. M. Williams, A. M. Kini, P. P. Sche, P. G. Nixon, R. W. Winter, G. L. Gard, D. Naumann, T. Roy, Synth. Met. (1997) 1533. 
[59] U. Geiser, J. A. Schlueter, J. D. Dudek, J. M. Williams, D. Naumann, T. Roy, Acta Cryst. C 51 (1995) 1779.

[60] H. Kobayashi, R. Kato, A. Kobayashi, Y. Nishio, K. Kajita, W. Sasaki, Chem. Lett. (1986) 833.

[61] J. A. Schlueter, U. Geiser, J. M. Williams, H. H. Wang, W. K. Kwok, J. A. Fendrich, K. D. Carlson, C. A. Achenbach, J. D. Dudek, D. Naumann, T. Roy, J. E. Schirber, W. R. Bayless, J. Chem. Soc., Chem. Commun. (1994) 1599. Kwok, J. A. Fendrich, U. Welp, P. M. Keane, J. D. Dudek, A. S. Komosa, D. Naumann, T. Roy, J. E. Schirber, W. R. Bayless, B. Dodrill, Physica C 233 (1994) 379.

J. A. Schlueter, J. M. Williams, U. Geiser, J. D. Dudek, S. A. Sirchio, M. E. Kelly, J. S. Gregar, W. H. Kwok, J. A. Fendrich, J. E. Schirber, W. R. Bayless, D. Naumann, T. Roy, J. Chem. Soc., Chem. Commun. (1995) 1311.

U. Geiser, J. A. Schlueter, H. H. Wang, J. M. Williams, D. Nauman, T. Roy, Acta Cryst. B 51 (1995) 789.

[65] U. Geiser, A. J. Schultz, H. H. Wang, D. M. Watkins, D. L. Stupka, J. M. Williams, J. E. Schirber, D. L. Overmyer, D. Jung, J. J. Novoa, M. H. Whangbo, Physica C 174 (1991) 475. 
[66] T. J. Emge, P. C. W. Leung, M. A. Beno, H. H. Wang, M. A. Firestone, K. S. Webb, K. D. Carlson, J. M. Williams, E. L. Venturini, L. J. Azevedo, J. E. Schirber, Mol. Cryst. Liq. Cryst. 132 (1986) 363-383.

J. M. Williams, H. H. Wang, T. J. Emge, U. Geiser, M. A. Beno, P. C. W. Leung, K. D. Carlson, R. J. Thorn, A. J. Schultz, M.-H. Whangbo In Progress in Inorganic Chemistry; John Wiley \& Sons: New York, 1987; pp 51.

[68] J. A. Schlueter, U. Geiser, H. H. Wang, M. E. Kelly, J. D. Dudek, J. M. Williams, D. Naumann, T. Roy, Mol. Cryst. Liq. Cryst. 284 (1996) 195.

[69] J. A. Schlueter, J. M. Williams, A. M. Kini, U. Geiser, J. D. Dudek, M. E. Kelly, J. P. Flynn, D. Naumann, T. Roy, Physica C 265 (1996) 163.

[70] J. A. Schlueter, J. M. Williams, U. Geiser, H. H. Wang, A. M. Kini, M. E. Kelly, J. D. Dudek, D. Naumann, T. Roy, Mol. Cryst. Liq. Cryst. 285 (1996) 43.

[71] H. Urayama, H. Yamochi, G. Saito, T. Sugano, M. Kinoshita, T. Inabe, T. Mori, Y. Maruyama, H. Inokuchi, Chem. Lett. (1988) 1057.

[72] V. Kataev, G. Winkel, D. Khomskii, D. Wohllenben, W. Crump, K. F. Tebbe, J. Hahn, Solid State Commun. 83 (1992) 435.

[73] U. Geiser, J. A. Schlueter, K. D. Carlson, J. M. Williams, H. H. Wang, W. K. Kwok, U. Welp, J. A. Fendrich, J. D. Dudek, C. A. Achenbach, A. S. Komosa, P. M. Keane, D. Naumann, T. Roy, J. E. Schirber, W. R. Bayless, J. Ren, M. H. Whangbo, Synth. Met. 70 (1995) 1105. 
[74] J. A. Schlueter, K. D. Carlson, J. M. Williams, H. H. Wang, U. Geiser, U. Welp, W. K. Kwok, J. A. Fendrich, J. D. Dudek, C. A. Achenbach, P. M. Keane, A. S. Komosa, D. Naumann, T. Roy, J. E. Schirber, W. R. Bayless, Physica C 230 (1994) 378.

[75] U. Geiser, J. A. Schlueter, J. M. Williams, A. M. Kini, J. D. Dudek, M. E. Kelly, D. Naumann, T. Roy, Synth. Met. (1997) 1465.

[76] K. Oshima, H. Urayama, H. Yamochi, G. Saito, Physica C 153-155 (1988) 1148.

[77] N. Toyota, T. Sasaki, Solid State Commun. 74 (1990) 361.

[78] T. Burgin, T. Meibach, J. C. Huffman, L. K. Montgomery, J. A. Paradis, C. Rovira, M. H. Whangbo, S. N. Magonov, S. I. Khan, C. E. Strouse, D. L. Overmyer, J. E. Schirber, J. Mater. Chem. 5 (1995) 1659.

[79] A. J. Graham, M. Kurmoo, P. Day, J. Chem. Soc., Chem. Commun. (1995) 2061.

[80] L. Martin, S. S. Turner, P. Day, F. E. Mabbs, E. J. L. McInnes, J. Chem. Soc., Chem. Commun. (1997) 1367-1368.

[81] M. Kurmoo, A. W. Graham, P. Day, S. J. Coles, M. B. Hursthouse, J. L. Caulfield, J. Singleton, F. L. Pratt, W. Hayes, L. Ducasse, P. Guionniau, J. Am. Chem. Soc. 117 (1995) 12209. 
[82] H. Yu, D. Zhu, Physica C 282-287 (1997) 1893. 


\section{Figure Captions}

Figure 1 Organic superconductors, such as $k-(E T)_{2} \mathrm{Cu}\left[\mathrm{N}(\mathrm{CN})_{2}\right] \mathrm{Br}$, are composed of organic conducting layers separated by non-conducting anion layers. This results in a material with very anisotropic conductivity, similar to that observed in the higher $T_{\mathrm{c}}$ cuprate superconductors.

Figure 2 The three most common packing motifs of the electron-donor molecule layer for ET-based superconducting salts. The $\kappa$-motif is characterized by orthogonal dimers and the $\beta$-motif by a honeycomb network. The. $\beta$ "-motif is related to the $\beta$-motif, except that the ET molecules are canted within the stacks. The dashed lines represent short contacts between the sulfur atoms in adjacent molecules through which conductivity occurs.

Figure 3 The top panel depicts a projection of the $(\mathrm{ET})_{2} \mathrm{Ag}\left(\mathrm{CF}_{3}\right)_{4}$ salt on the $b c$ plane. The lower panel shows a similar projection of the $(\mathrm{ET})_{2} \mathrm{Ag}\left(\mathrm{CF}_{3}\right)_{2}(\mathrm{CN})_{2}$ structure.

Figure $4 \mathrm{~A})$ The disordered $M\left(\mathrm{CF}_{3}\right)_{4}^{-}$anion as crystallized in the $\kappa_{\mathrm{L}^{-}}$ $(\mathrm{ET})_{2} M\left(\mathrm{CF}_{3}\right)_{4}(1,1,2$-trihaloethane $)$ and $\kappa_{\mathrm{L}}$-(BEDT-TSF $)_{2} \mathrm{Ag}\left(\mathrm{CF}_{3}\right)_{4}(\mathrm{TCE})$ structures. B) The ordered $M\left(\mathrm{CF}_{3}\right)_{4}^{-}$anion as crystallized in the $(\mathrm{ET})_{2} M\left(\mathrm{CF}_{3}\right)_{4}$ salts. C) The $\mathrm{Ag}\left(\mathrm{CF}_{3}\right)_{2}(\mathrm{CN})_{2}^{-}$anion as crystallized in the $(\mathrm{ET})_{2} \mathrm{Ag}\left(\mathrm{CF}_{3}\right)_{2}(\mathrm{CN})_{2}$ salt. D) The $\mathrm{Ag}\left(\mathrm{CF}_{3}\right)_{3} \mathrm{Cl}^{-}$anion as crystallized in the $\kappa_{\mathrm{L}}$-(BEDT-TSF $)_{2} \mathrm{Ag}\left(\mathrm{CF}_{3}\right)_{3} \mathrm{Cl}(\mathrm{TCE})$ structure.

Figure 5 Four-probe variable temperature conductivity as measured along the needle-like axis of a single crystal of the $(\mathrm{ET})_{2} \mathrm{Ag}\left(\mathrm{CF}_{3}\right)_{4}$ salt. The inset 
shows that the electical conductivity follows an Arrhenius-type conductivity model.

Figure $6 \mathrm{~A}$ comparison of the crystal structures of two $\kappa$-phase organic superconductors: $\mathrm{k}-(\mathrm{ET})_{2} \mathrm{Cu}\left[\mathrm{N}(\mathrm{CN})_{2}\right] \mathrm{Br}$ and $\kappa_{\mathrm{L}}-(\mathrm{ET})_{2} \mathrm{Cu}\left(\mathrm{CF}_{3}\right)_{4}(\mathrm{TCE})$. The anion layer in $\mathrm{k}_{\mathrm{L}}$-(ET) $)_{2} \mathrm{Cu}\left(\mathrm{CF}_{3}\right)_{4}(\mathrm{TCE})$ is more than twice as thick as in $\mathrm{K}$ $(\mathrm{ET})_{2} \mathrm{Cu}\left[\mathrm{N}(\mathrm{CN})_{2}\right] \mathrm{Br}$. Disorder within the anion layer may result in the lower $T_{\mathrm{c}}$ found in the $\mathrm{K}_{\mathrm{L}}-(\mathrm{ET})_{2} \mathrm{Cu}\left(\mathrm{CF}_{3}\right)_{4}(\mathrm{TCE})$ salt.

Figure 7 The disordered solvent molecule in the $\mathrm{K}_{\mathrm{L}}-(\mathrm{ET})_{2} M\left(\mathrm{CF}_{3}\right)_{4}(1,1,2-$ trihaloethane) structures. The halogen positions of the two differant orientations of the solvent molecule occupy the corners of the same isosceles triangle. Halogen site $\mathrm{A}$ lies on a mirror plane, while sites $\mathrm{B}$ and $\mathrm{B}^{\prime}$ are mirror symmetric. The three types of 1,1,2-trihaloethane solvent molecules shown have crystallized into this structural type.

Figure 8 The superconducting transition temperature in $\kappa_{\mathrm{L}}-(\mathrm{ET})_{2} \mathrm{Ag}\left(\mathrm{CF}_{3}\right)_{4}(1,1,2-$ trihaloethane) salts can be controlled through the use of mixed solvents in the electrocrystallization step. Illustrated are the variable temperature ac susceptibility curves obtained from several single crystals grown from the following solvent mixtures: $\Delta 100 \%$ trichloroethane, $\boldsymbol{\nabla} 50 \%$ trichloroethane / $50 \%$ tribromoethane, $25 \%$ trichloroethane / $25 \%$ tribromoethane, $100 \%$ tribromoethane.

Figure 9 The crystal structure of $\mathrm{K}_{\mathrm{L}}$-(BEDT-TSF) $)_{2} \mathrm{Ag}\left(\mathrm{CF}_{3}\right)_{4}(\mathrm{TCE})$ illustrated as a projection on the $a b$-plane. 
Figure 10Atomic numbering scheme for the $(\mathrm{ET})_{2} \mathrm{Ag}\left(\mathrm{CF}_{3}\right)_{2}(\mathrm{CN})_{2}$ structure.

Figure 11Atomic numbering scheme for the $\kappa_{\mathrm{L}}$-(BEDT-TSF) ${ }_{2} \mathrm{Ag}\left(\mathrm{CF}_{3}\right)_{4}(\mathrm{TCE})$ structure. 


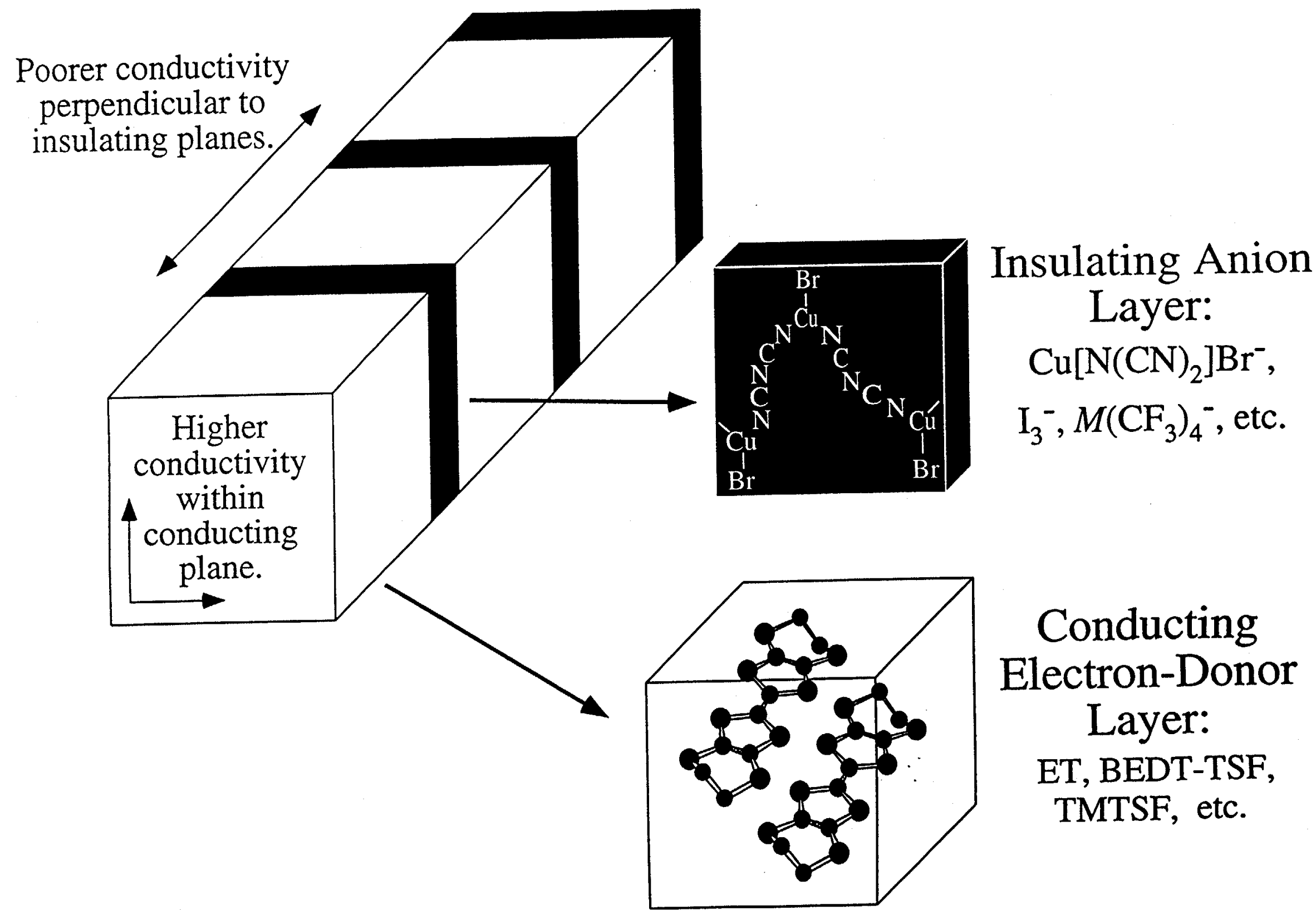

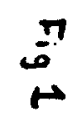




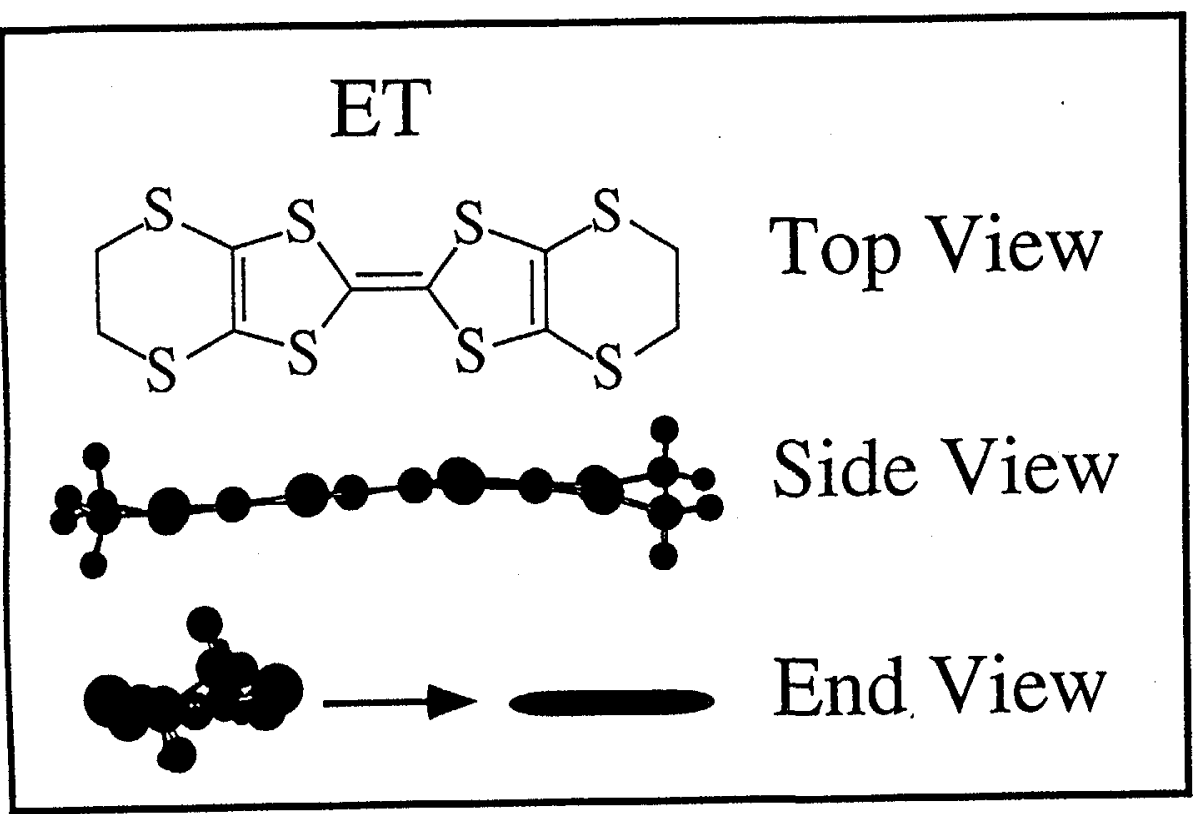

$\beta$-phase

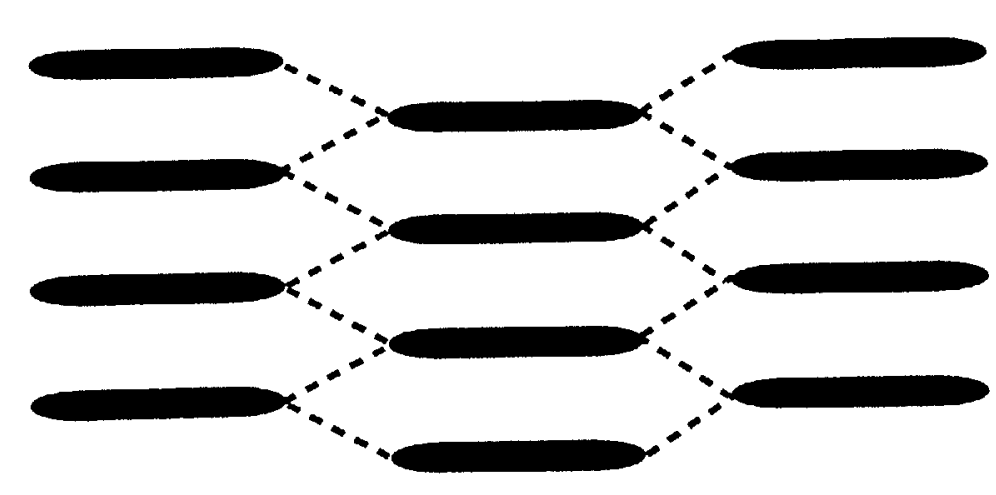

K-phase

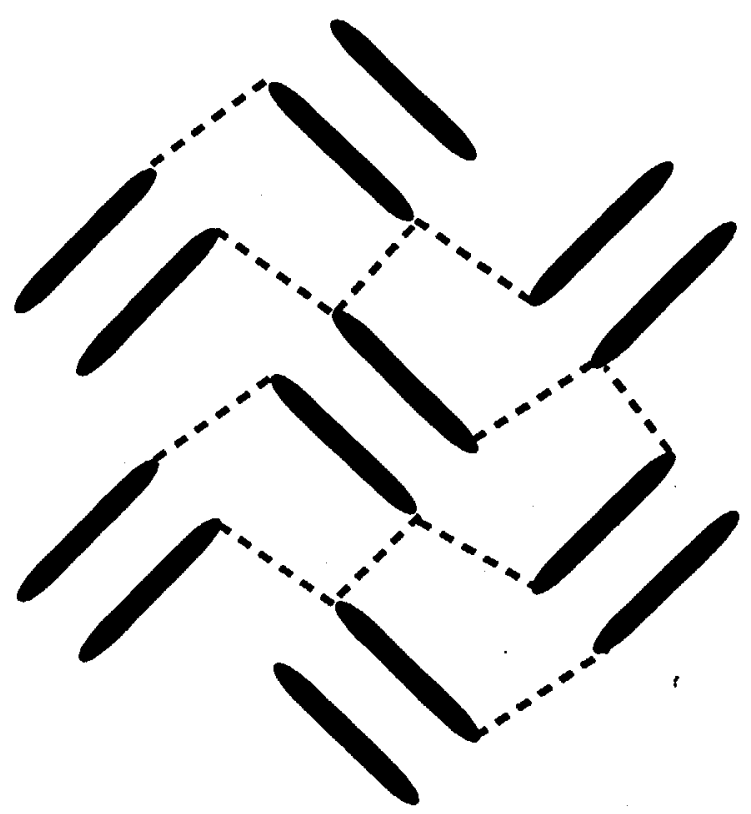

$\beta "$-phase

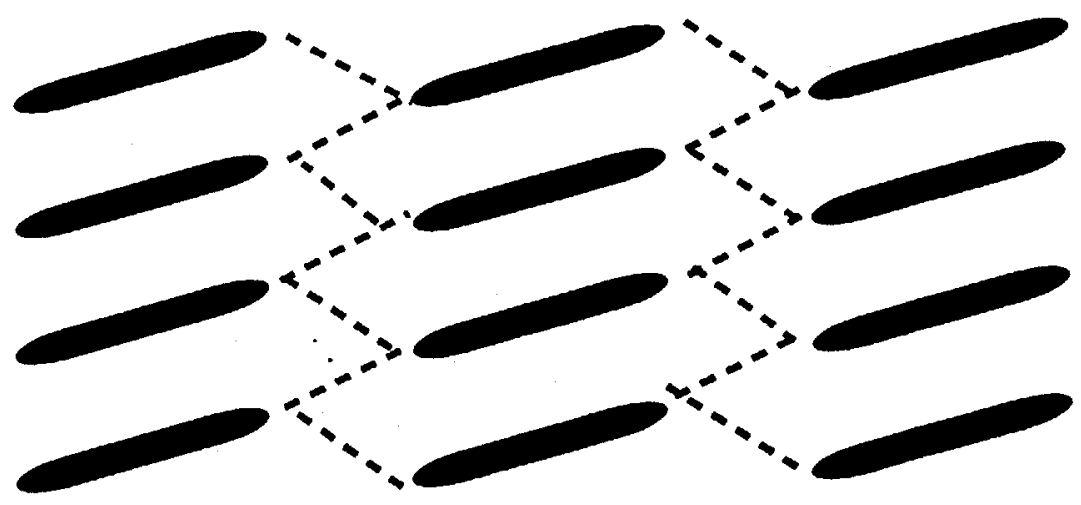




\section{$(\mathrm{ET})_{2} \mathrm{Ag}\left(\mathrm{CF}_{3}\right)_{4}$}

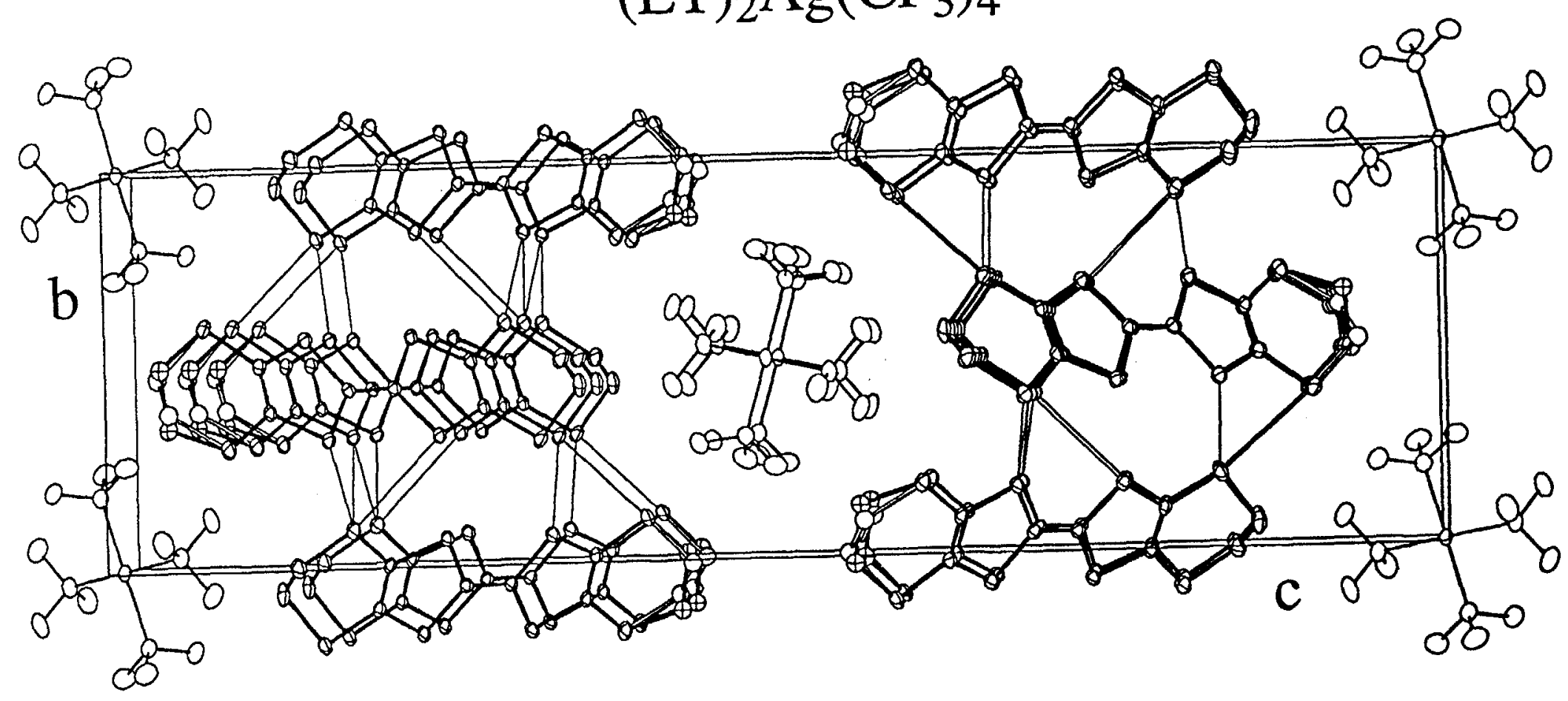

$(\mathrm{ET})_{2} \mathrm{Ag}\left(\mathrm{CF}_{3}\right)_{2}(\mathrm{CN})_{2}$

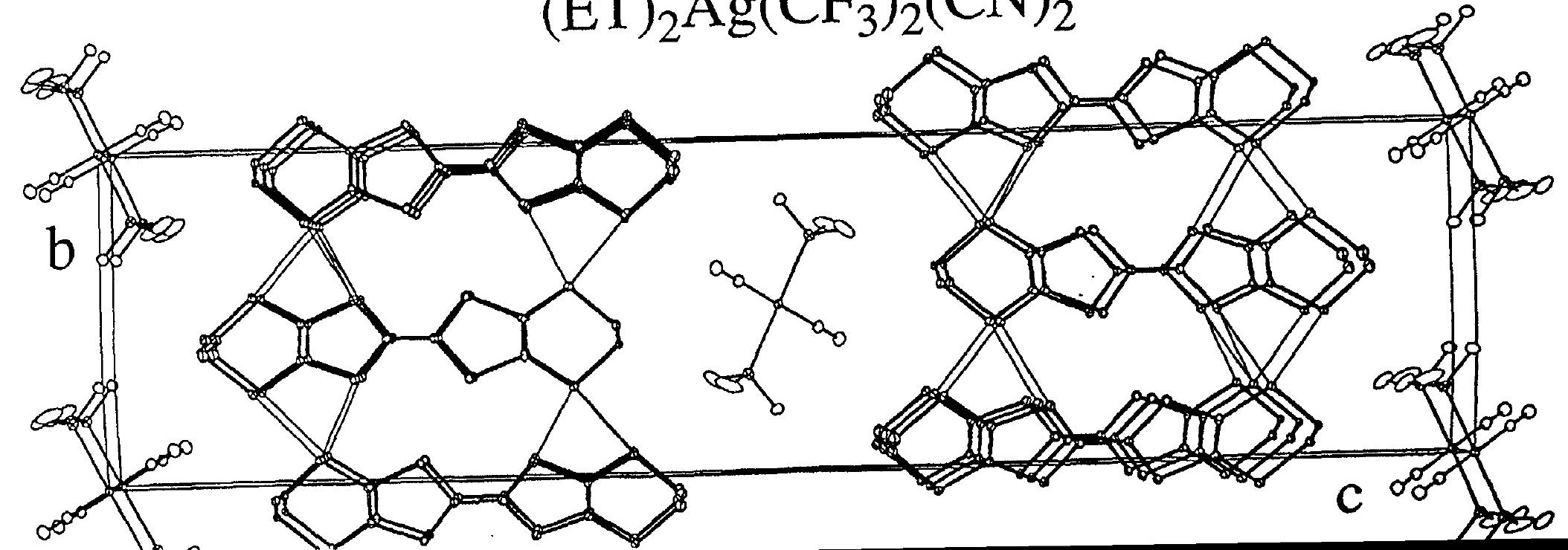



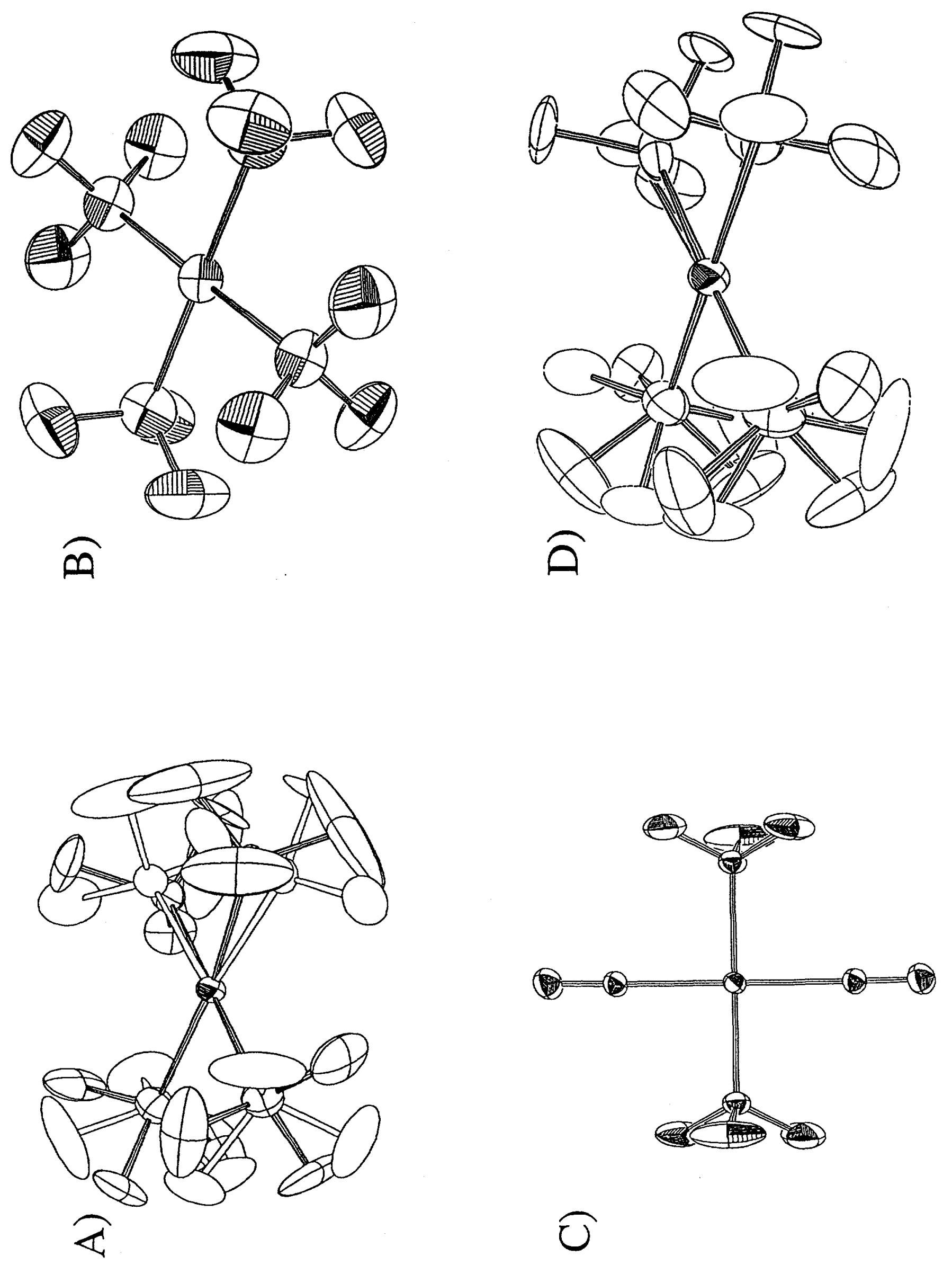


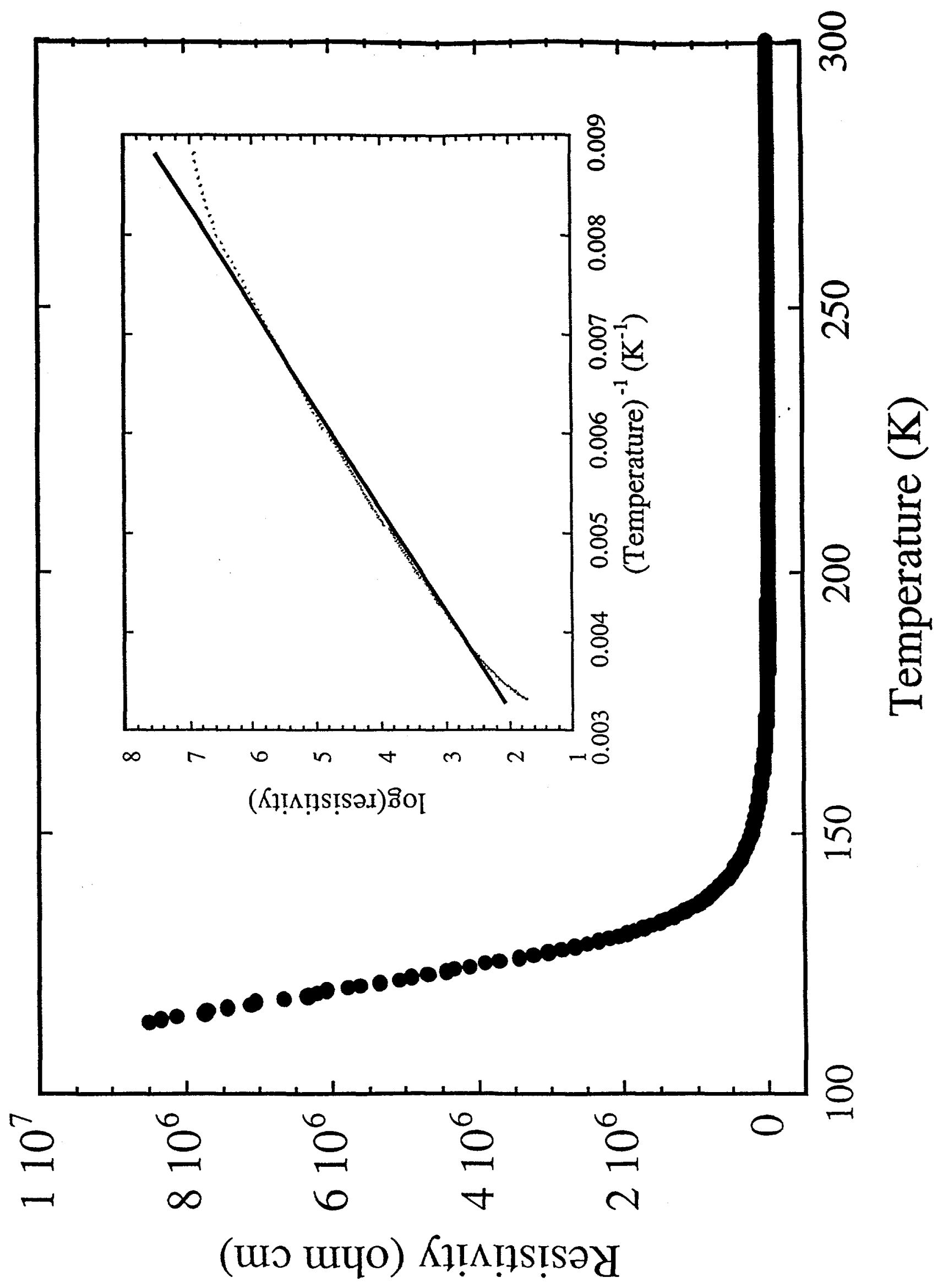




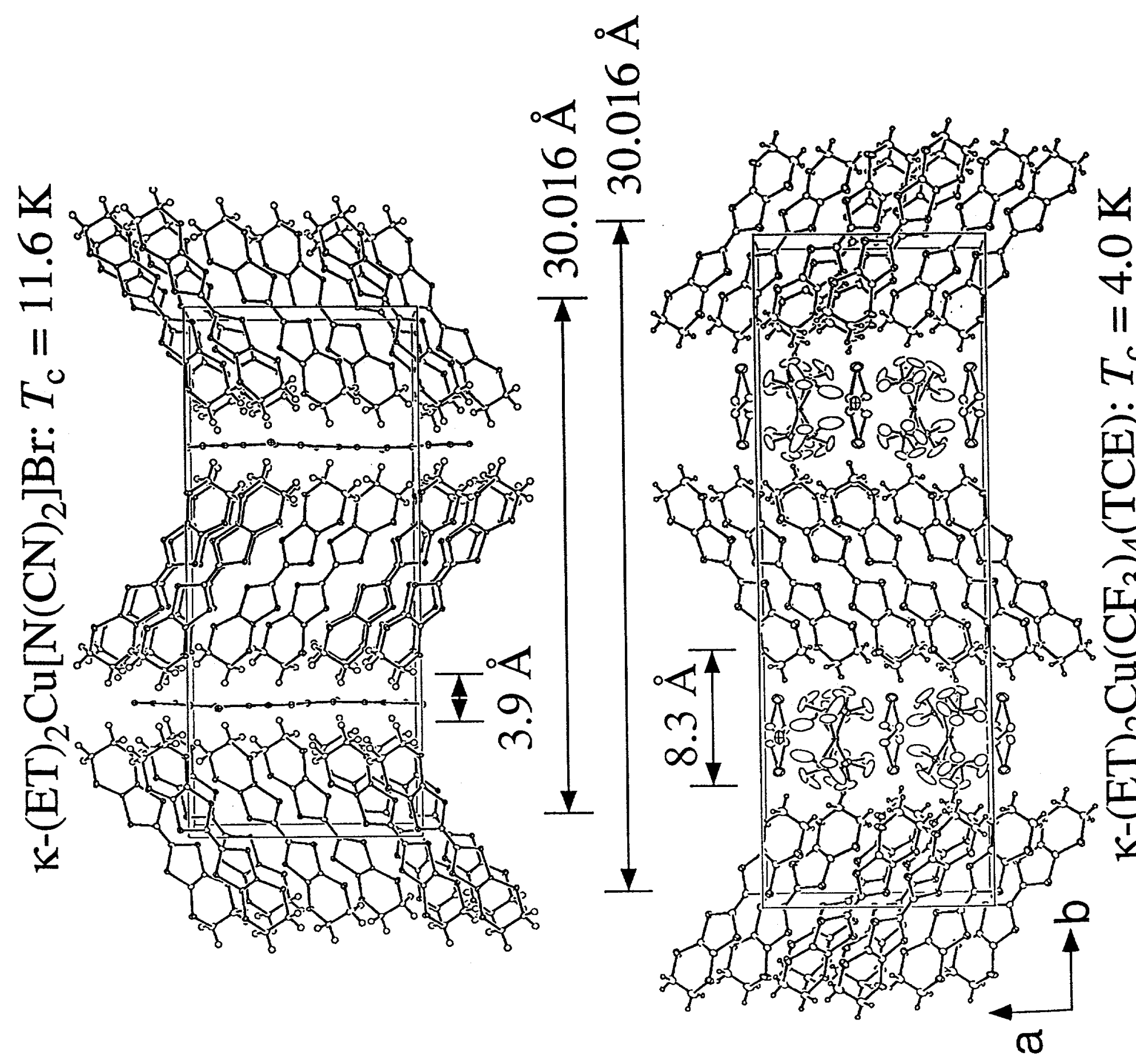




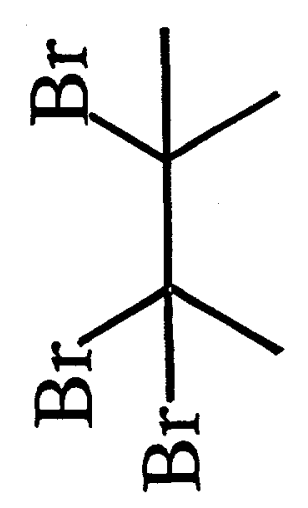

(1)

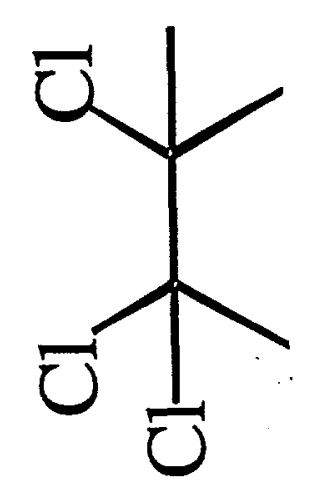

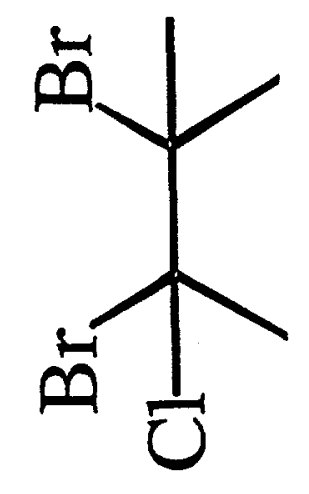

(1)

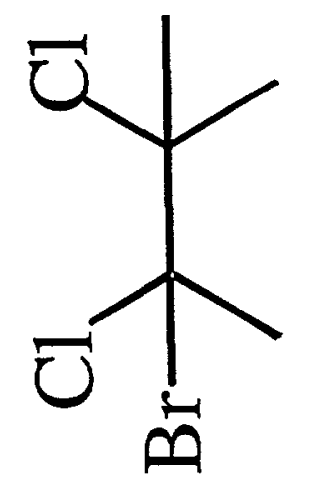

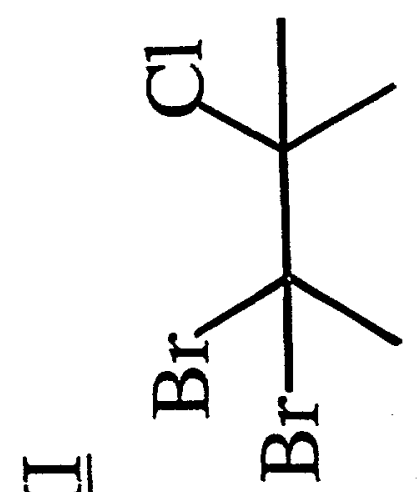

(1)

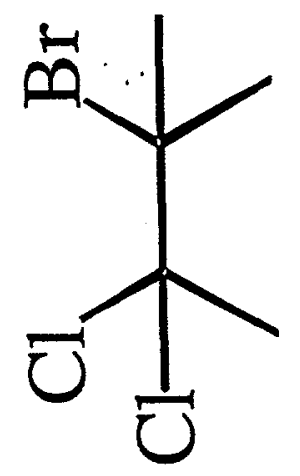

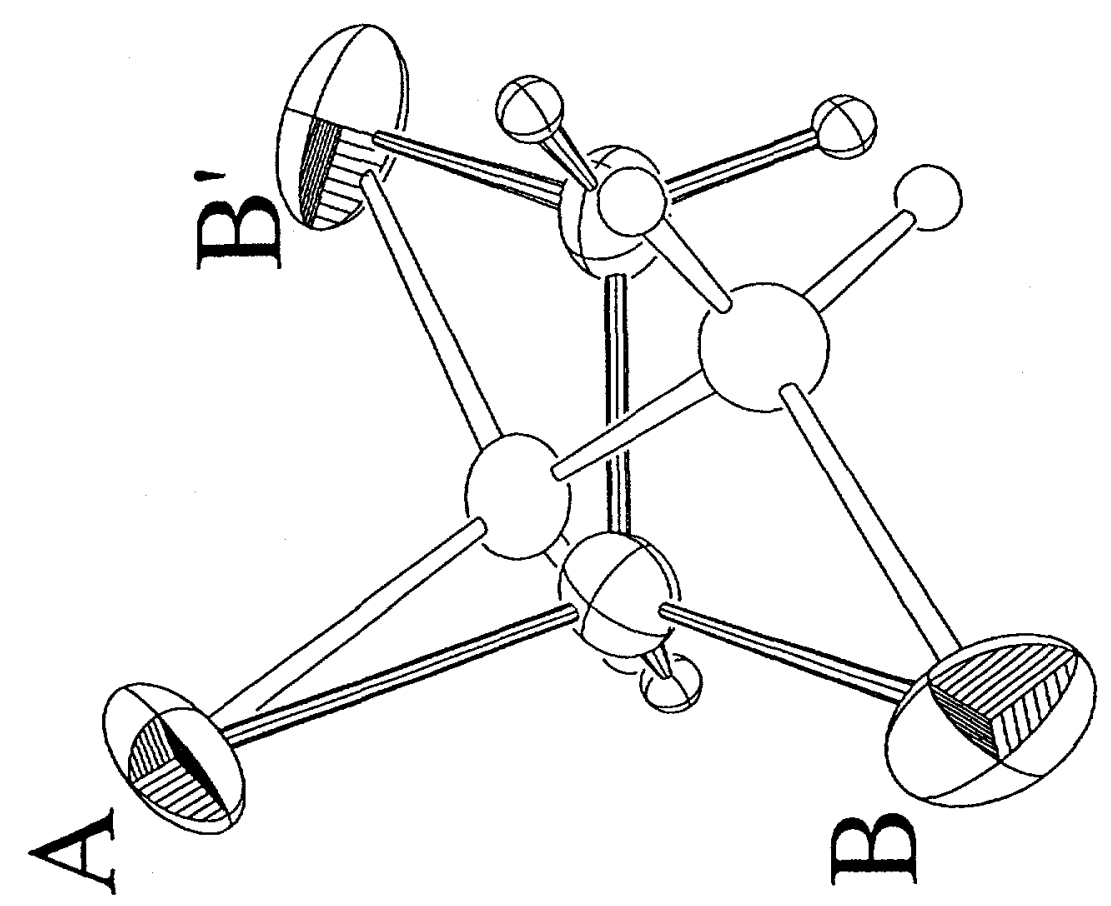




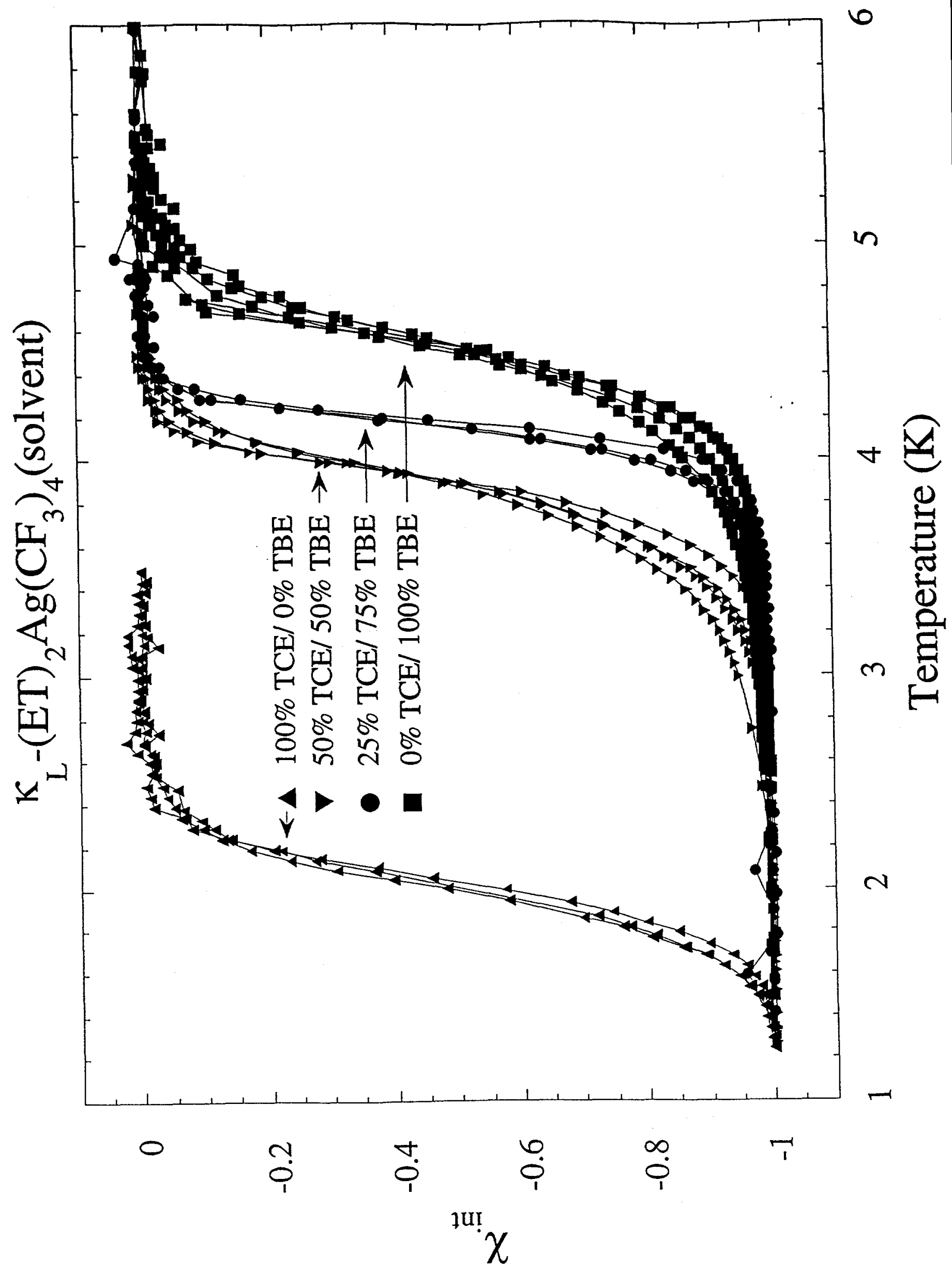




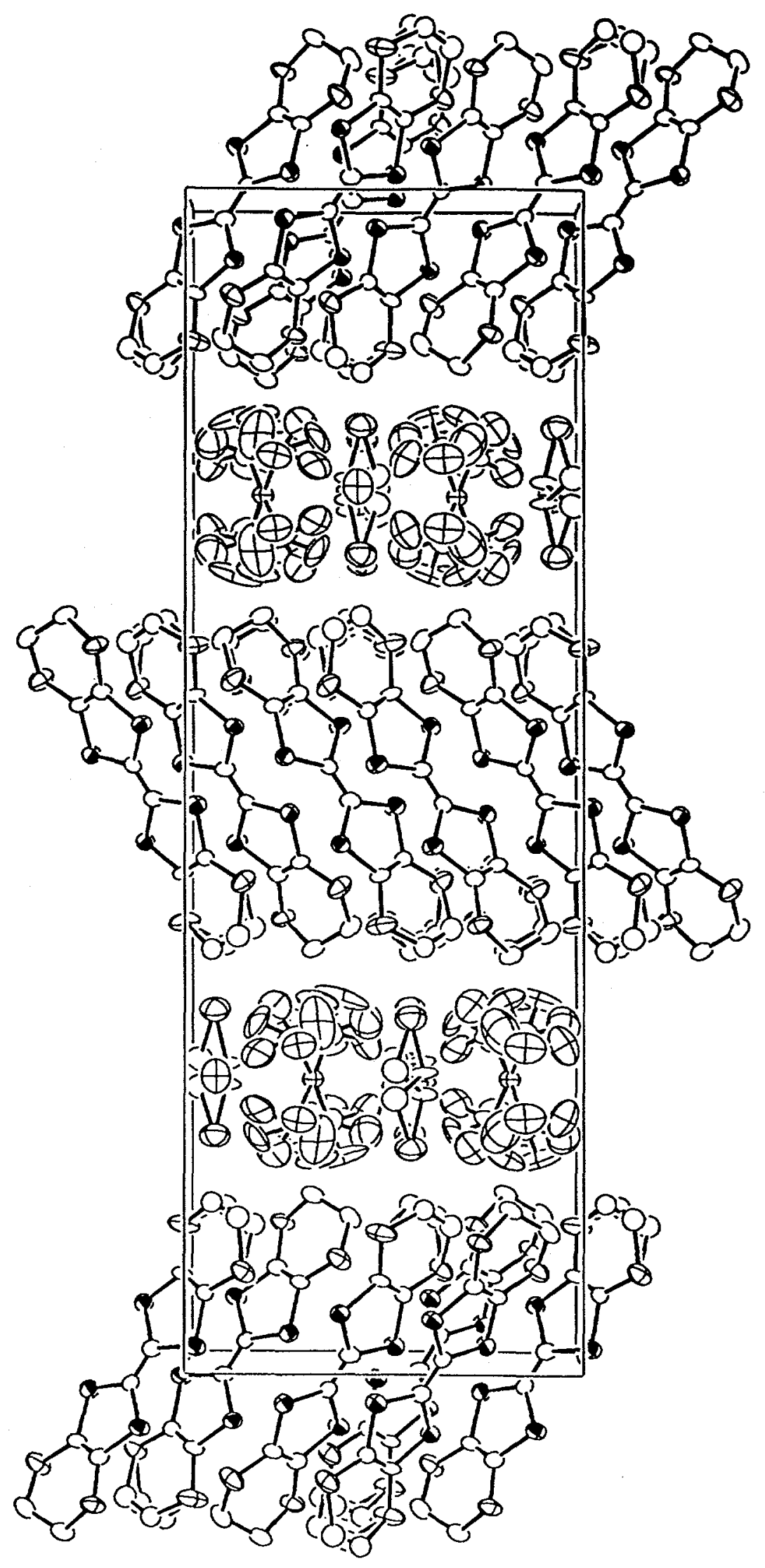



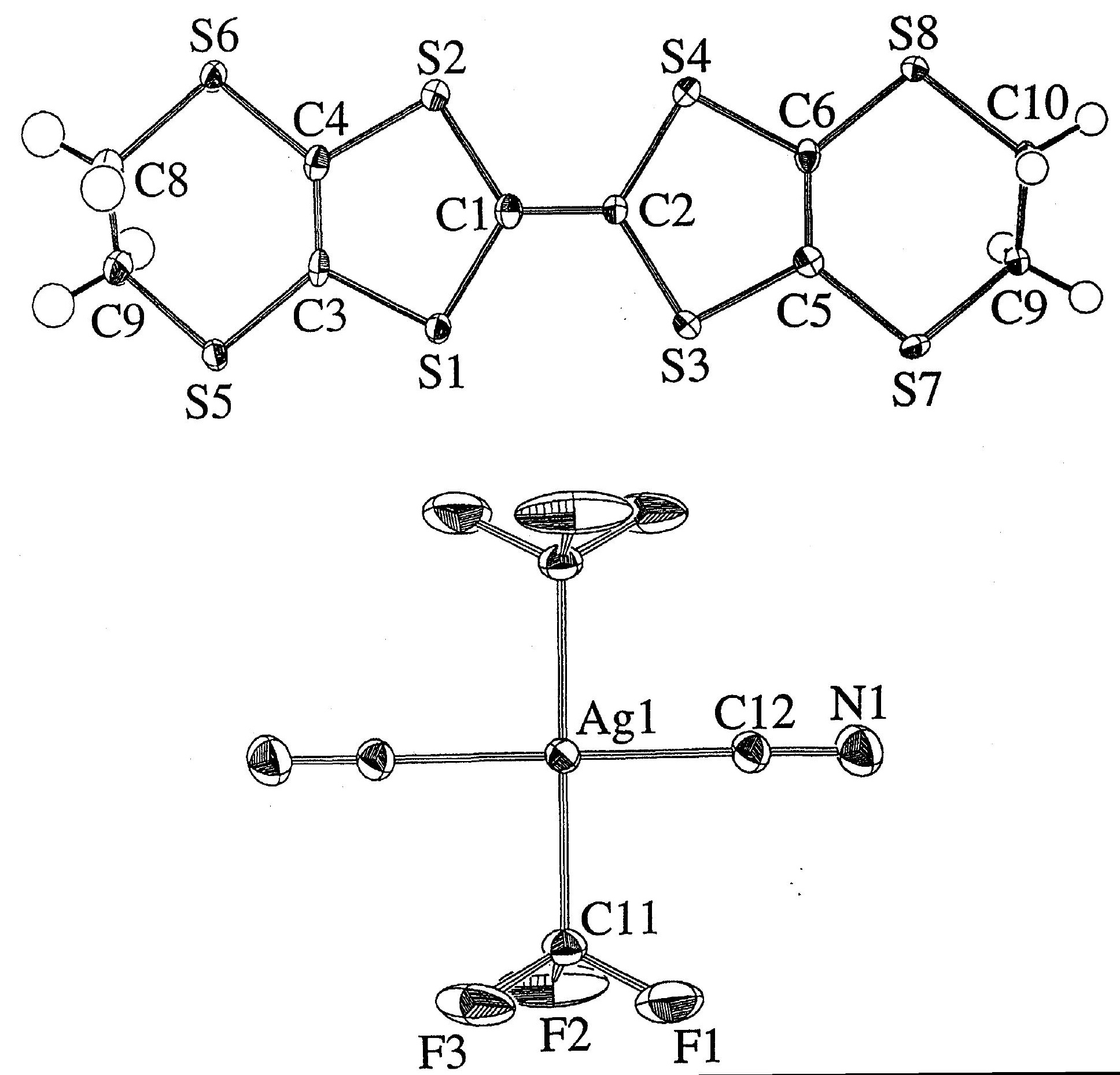

تِق 

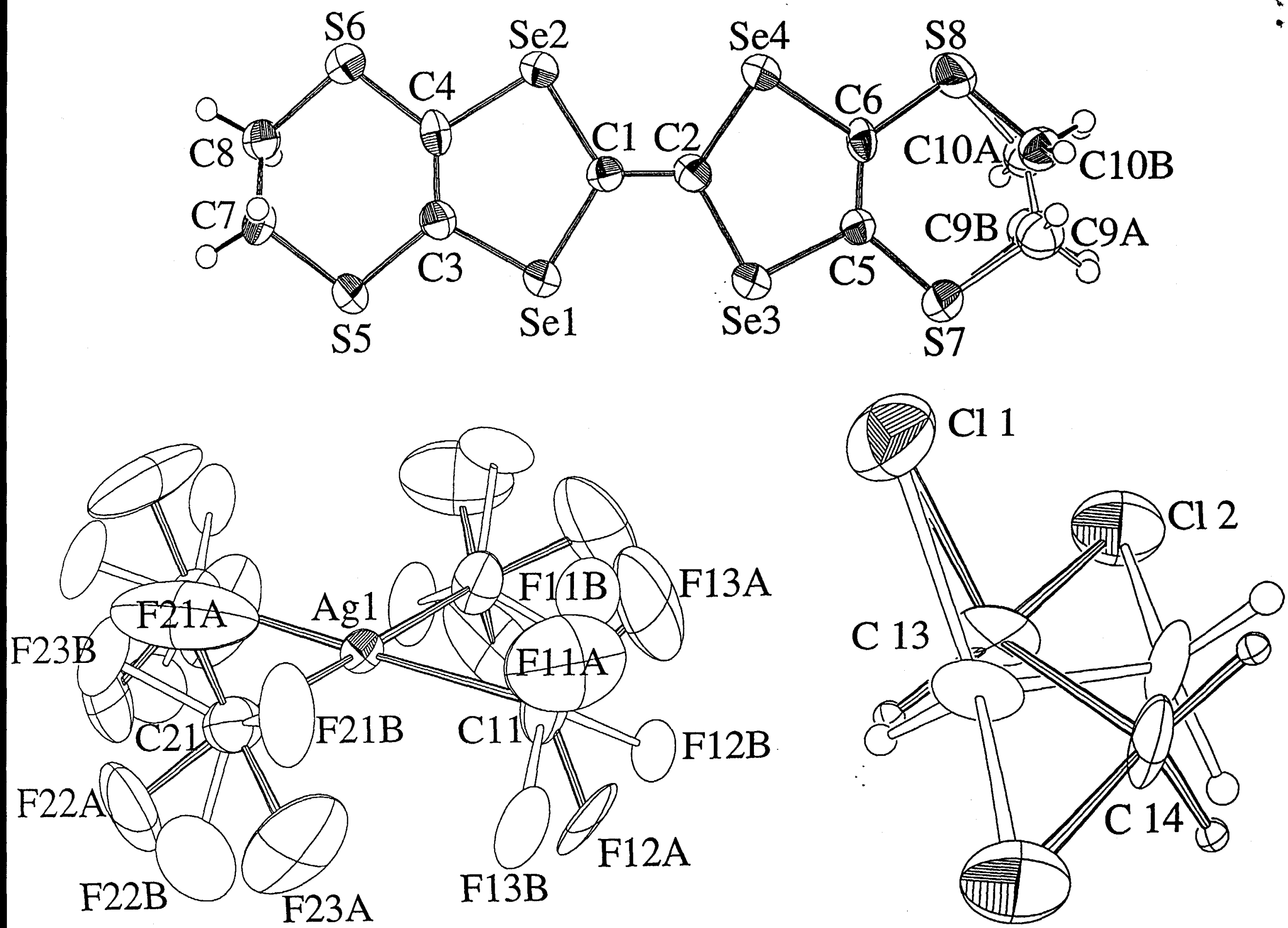